\title{
RUPTURE MODEL OF THE 1989 LOMA PRIETA EARTHQUAKE FROM THE INVERSION OF STRONG-MOTION AND BROADBAND TELESEISMIC DATA
}

\author{
By David J. Wald, Donald V. Helmberger, and Thomas H. Heaton
}

\begin{abstract}
We have used 24 broadband teleseismic and 48 components of local strong-motion velocity records of the 1989 Loma Prieta earthquake in a formal inversion to determine the temporal and spatial distribution of slip. Separate inversions of the teleseismic data (periods of 3 to $30 \mathrm{sec}$ ) or strong-motion data (periods of 1 to $5 \mathrm{sec}$ ) result in similar models. The data require bilateral rupture with relatively little slip in the region directly updip from the hypocenter. Slip is concentrated in two patches: one centered $6 \mathrm{~km}$ northwest of the hypocenter at a depth of $12 \mathrm{~km}$ and with a maximum slip of $350 \mathrm{~cm}$, and the other centered about $5 \mathrm{~km}$ southeast of the hypocenter at a depth of $16 \mathrm{~km}$ and with a maximum slip of $460 \mathrm{~cm}$. The bilateral nature of the rupture results in large amplitude ground motions at sites located along the fault strike, both to the northwest and the southeast. However, the northwestern patch has a larger moment and overall stress drop and is, consequently, the source of the largest ground motion velocities, consistent with the observed recordings. This bilateral rupture also produces relatively modest ground motion amplitudes directly updip from the hypocenter, which is in agreement with the velocity ground motions observed at Corralitos. There is clear evidence of a foreshock (magnitude between 3.5 and 5.0 ) or a slow rupture nucleation about $2 \mathrm{sec}$ before the main part of the rupture; the origin time implied by strong-motion trigger times is systematically $2 \mathrm{sec}$ later than the time predicted from the high-gain regional network data. The seismic moment obtained from either of the separate data sets or both sets combined is about $3.0 \times 10^{26}$ dyne-cm and the potency is $0.95 \mathrm{~km}^{3}$.
\end{abstract}

\section{INTRODUCTION}

In this study, we use a least-squares linear inversion of strong motion and teleseismic waveform data to solve for the temporal and spatial distribution of slip vectors during the 1989 Loma Prieta earthquake $\left(M_{s}=7.1\right)$. Although the geometry of the fault plane is fixed in the inversion, it is chosen to be compatible with teleseismic waveforms and the distribution of aftershocks. Our estimates of the spatial and temporal distribution of slip will enhance studies of fault segmentation and earthquake recurrence (King et al., 1990; Working Group on California Earthquake Probabilities, 1988), which depend on reliable estimates of the rupture dimensions and amplitude of slip. Furthermore, the variation in rake angle as a function of position along strike and downdip on the fault plane is critical to analyses of the complicated fault interactions within the Sargent-San Andreas system (Dietz and Ellsworth, 1990; Michael et al., 1990; Olson, 1990; Schwartz et al., 1990; Seeber and Armbruster, 1990).

The method we employ is that of Hartzell and Heaton (1983), which has been shown to provide valuable insight into the rupture history of other California earthquakes (Hartzell and Heaton, 1983; Hartzell and Heaton, 1986; Hartzell, 1989; Wald et al., 1990), as have other finite fault approaches (Olson and Apsel, 1982; Archuleta, 1984; Beroza and Spudich, 1988). In addition to providing an 
estimate of the rupture history for individual earthquakes, these studies also provide new insight into the general characteristics of the rupture process that are common to many events. After studying slip models from several earthquakes, Mendoza and Hartzell (1988) suggested that large gaps in aftershock patterns often coincide with the regions of relatively large slip. From the distribution of slip, we can also place constraints on the location and depth extent of significant energy release and characterize the distribution of stress changes on the faults. These results provide a starting point for calculating ground motions for future events comparable to size to the Loma Prieta earth. quake. Such ground motion calculations are important for augmenting the sparse data base of near-source strong-motion recordings of crustal earthquakes having magnitudes of 7 or larger.

The Loma Prieta earthquake was well recorded at both local strong-motion and teleseismic broadband stations. The strong-motion velocity recordings used here are dominated by energy in the range of 1 to $5 \mathrm{sec}$, while the broadband teleseismic recordings range from 3 to $30 \mathrm{sec}$. This wealth of data provides an opportunity to compare rupture models that are derived independently from either the strong-motion or the teleseismic waveforms with models derived from the combined data sets and over a wide range of frequencies. Our results provide insight into the limitations and constraints provided by previous studies that have less extensive data sets.

\section{DATA}

Ground motions from the Loma Prieta earthquake were recorded over a wide range of frequencies and distances, from high-frequency waveforms on local accelerometers and regional seismic networks to very low frequencies observed in teleseismic surface waves and geodetic line length changes. Unfortunately, deterministic waveform inversion of high-frequency motion $(>3 \mathrm{~Hz}$ ) requires an accurate and detailed knowledge of the wave propagation in the geologically complex structure in the Loma Prieta region. Furthermore, inversion of high frequencies requires a proliferation of free variables that significantly increase the computation time and decrease the stability of the inversion process. Therefore, we have chosen to concentrate our study on the lower frequency part of the rupture history. Near-source low-pass-filtered strong-motion and teleseismic body waves seem to be the most suitable data sets to study the general characteristics of the slip history. Geodetic data can also provide important constraints on an earthquake slip distribution model. Unfortunately, we were not able to obtain enough geodetic data at the time of this study to justify its inclusion in the formal inversion process.

\section{Teleseismic}

The teleseismic stations chosen for this study are listed in Table 1 . The data are digital recordings obtained from the Chinese Digital Seismograph Network (CDSN), GEOSCOPE and Incorporated Research Institution for Seismology (IRIS) broadband components, and Global Digital Seismograph Network (GDSN) intermediate-period components. These stations provide a uniform azimuthal coverage of the focal sphere and also contain several near-nodal observation for both $P$ and $S H$ source radiation( Fig. 1). In this analysis, instrument responses were deconvolved from the original recordings to obtain true ground velocities. 
TABLE 1

Teleseismic Stations

\begin{tabular}{|c|c|c|c|c|}
\hline Station & $\begin{array}{c}\text { Distance } \\
\left({ }^{\circ}\right)\end{array}$ & Azimuth & Backazimuth & $\begin{array}{c}\text { Phasas } \\
\text { Used }\end{array}$ \\
\hline AFI & 69.2 & 232.6 & 40.8 & $P, S H$ \\
\hline ARU & 86.9 & 359.7 & 0.4 & $P, S H$ \\
\hline CAY & 70.8 & 98.6 & 307.6 & $p, S H$ \\
\hline $\mathrm{COL}$ & 31.8 & 339.4 & 138.5 & $P$ \\
\hline HIA & 77.9 & 324.0 & 45.9 & $P$ \\
\hline HON & 35.0 & 253.5 & 55.2 & $P$ \\
\hline HRV & 38.5 & 65.7 & 279.2 & $P$ \\
\hline MDJ & 76.0 & 305.2 & 51.3 & $P$ \\
\hline NNA & 64.8 & 130.1 & 321.5 & $P, S H$ \\
\hline OBN & 85.1 & 11.9 & 343.0 & $P, S H$ \\
\hline PPT & 60.5 & 210.6 & 25.2 & $P, S H$ \\
\hline RPN & 65.2 & 167.7 & 349.0 & $P, S H$ \\
\hline SCP & 34.1 & 67.8 & 278.3 & $P$ \\
\hline SSB & 84.6 & 34.7 & 319.8 & $P$ \\
\hline TOL & 84.3 & 43.0 & 314.8 & $P, S H$ \\
\hline WFM & 38.5 & 65.6 & 279.1 & $P$ \\
\hline
\end{tabular}
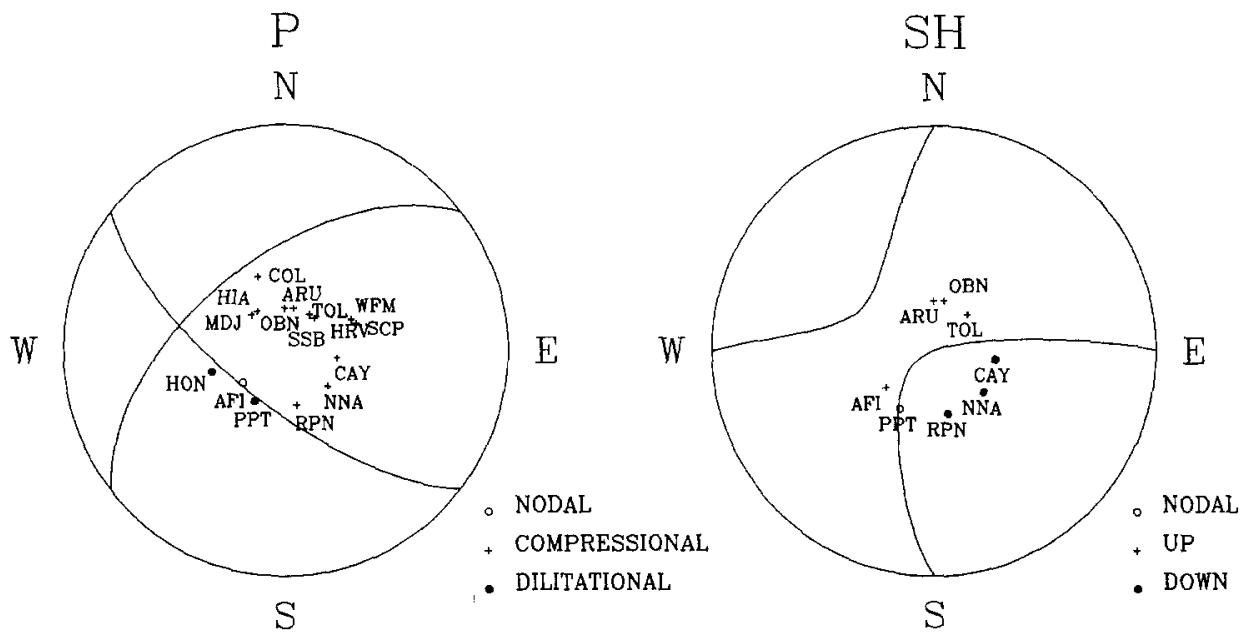

Fig. 1. Global station distribution for teleseismic records shown by takeoff angles plotted on focal spheres. The $P$ (left) and $S H$ (right) radiation patterns are given for a mechanism with strike, dip, and rake equal to $128^{\circ}, 70^{\circ}$, and $138^{\circ}$, respectively. For $S H$, up refers to clockwise motion.

\section{Strong Motion}

The distribution of near-source ground velocities used in this study is displayed in Figures $2 a$ to c. Station abbreviations, station geometries with respect to the epicenter, and trigger times (when available) are given in Table 2. The velocity waveforms were obtained by integrating corrected acceleration recordings provided by the CDMG (Shakal et al., 1989) and the USGS (Maley et al., 1989) and uncorrected recordings from the University of California Santa Cruz (UCSC). The velocity waveforms were bandpass filtered between 0.1 and $1.0 \mathrm{~Hz}$ using a zero-phase third-order, Butterworth filter. The horizontal components 


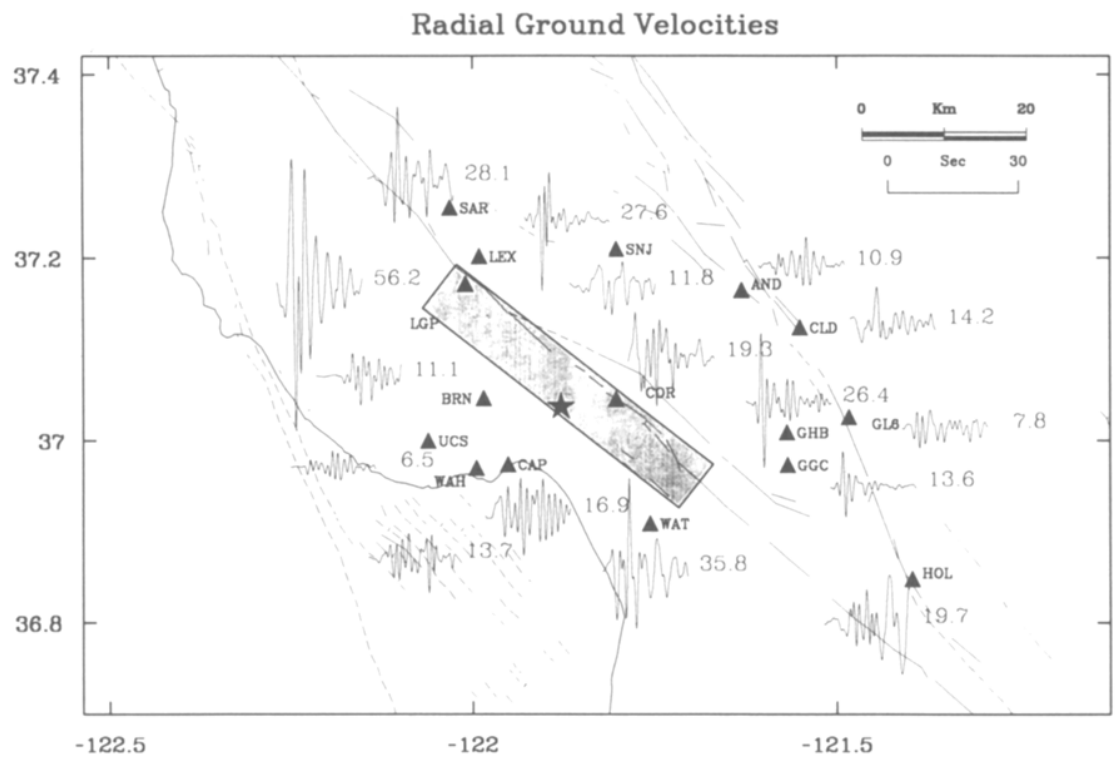

(a)

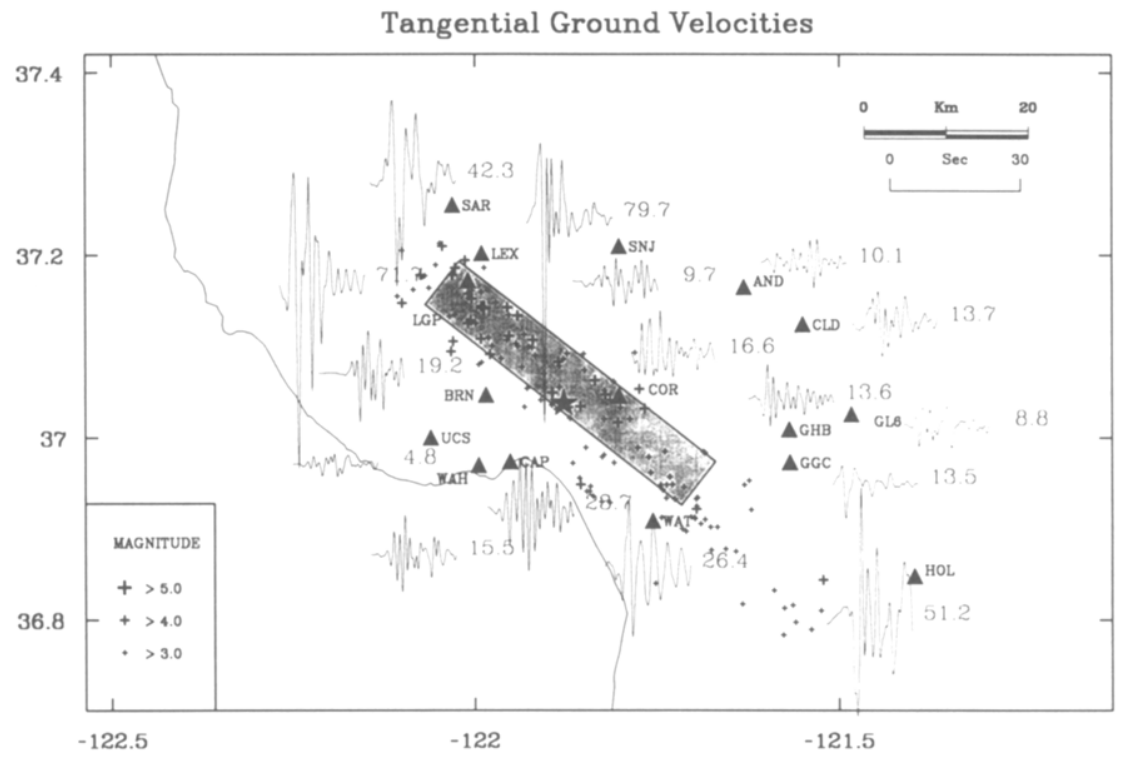

(b)

FIG. 2. (a) Location map showing strong-motion stations (solid triangles). The shaded region represents the surface projection of the model fault plane used in this study. The epicenter is shown with a star. Radial ground velocities are displayed for each of the stations. Amplitudes are in $\mathrm{cm} / \mathrm{sec}$. The faults are a digitized version of major Quaternary faults of Jennings (1975). (b) Same as (a) except Tangential ground velocity is shown. Also shown in the distribution of aftershocks. (c) Same as (a) except vertical ground velocity is shown. Also shown is the Modified Mercalli isoseismal contour separating regions of intensity VII and VIII (from Stover et al., 1990).

are rotated with respect to the epicenter to obtain radial and tangential components. While this rotation is correct for the energy originating near the epicenter, it is only approximate for source regions further northwest and southeast along the fault. 


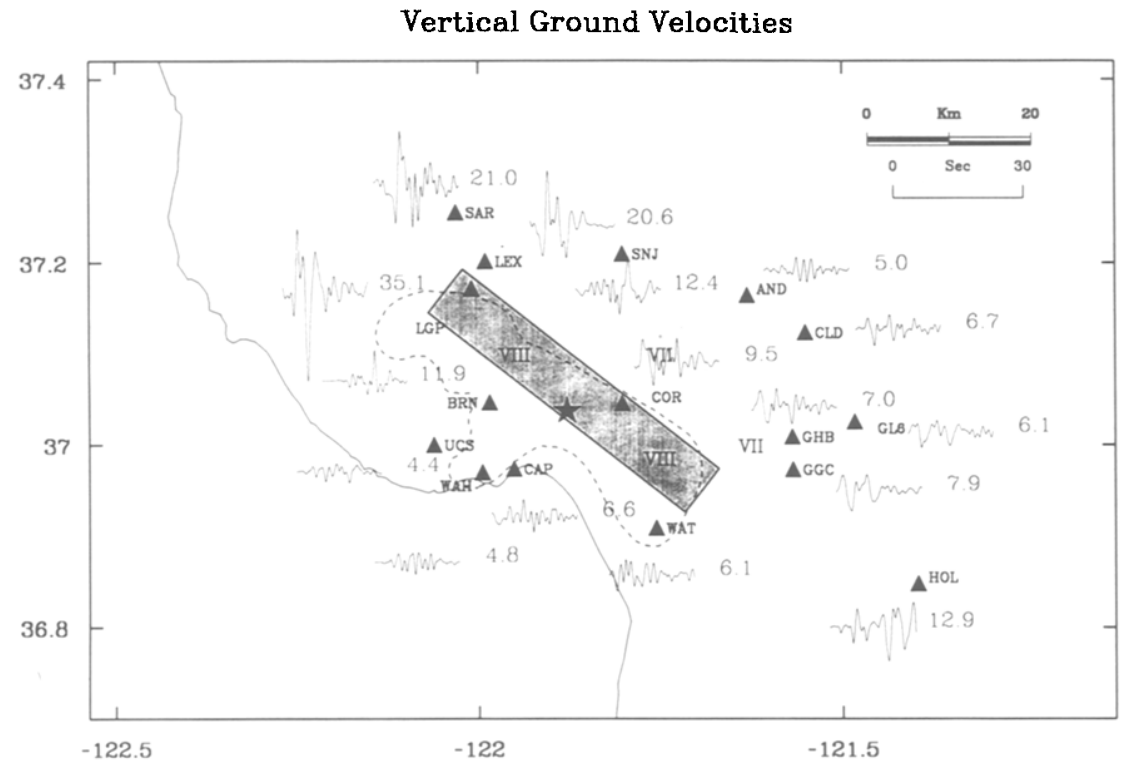

(c)

FIG. 2. (Continued)

TABLE 2

Loma Prieta Strong-Motion Stations

\begin{tabular}{cllrrrrr}
\hline Abbreviation & \multicolumn{1}{c}{ Station Name } & $\begin{array}{c}\text { Data } \\
\text { Source }\end{array}$ & $\begin{array}{c}\text { Distance* } \\
(\mathbf{k m})\end{array}$ & Azimuth* $^{*}$ & $\begin{array}{c}\text { Station } \\
\text { Delay }^{\dagger}\end{array}$ & $\begin{array}{c}\text { Trigger } \\
\text { Times }^{\ddagger}\end{array}$ & $\begin{array}{c}\text { Trigger } \\
- \text { - T. } \S\end{array}$ \\
\hline AND & Anderson Dam & USGS & 26.1 & 57.6 & 0.0 & 23.0 & 7.8 \\
BRN & Branciforte Drive & UCSC & 9.5 & 275.4 & - & - & - \\
CAP & Capitola Fire Station & CDMG & 9.7 & 222.0 & - & - & - \\
CLD & Coyote Lake Dam & GDMG & 30.7 & 72.1 & 0.0 & 24.5 & 9.3 \\
COR & Corralitos & CDMG & 6.8 & 83.5 & 0.0 & 20.4 & 5.2 \\
GGC & Gavilan College & CDMG & 28.6 & 104.8 & -0.4 & 23.9 & 8.7 \\
GHB & Gilroy Hist. Bldg. & CDMG & 27.8 & 96.9 & -0.2 & 23.4 & 8.2 \\
GL6 & Gilroy Array 6 & CDMG & 35.2 & 92.4 & 0.7 & 26.0 & 10.8 \\
HOL & Hollister-Pine St & CDMG & 47.9 & 116.3 & 1.9 & 27.5 & 12.3 \\
LEX & Lexington Dam & CDMG & 19.1 & 331.0 & -0.3 & 21.1 & 5.9 \\
LGP & Los Gatos Pres. Cent. & UCSS & 18.8 & 321.7 & - & - & - \\
SAR & Saratoga-Aloha Ave & CDMG & 27.5 & 330.6 & - & - & - \\
SNJ & San Jose-Harry Rd & CDMG & 20.1 & 19.6 & -0.2 & 18.3 & $3.1 \#$ \\
UCS & U.C. Santa Cruz & UCSC & 16.8 & 255.0 & - & - & - \\
WAH & Walter's House & UCSC & 12.9 & 233.4 & - & - & - \\
WAT & Watsonville & CDMG & 18.1 & 142.8 & 0.3 & 21.6 & 6.4 \\
\hline
\end{tabular}

*With respect to epicenter at $37^{\circ} 2.37^{\prime} \mathrm{N} 121^{\circ} 52.81^{\prime} \mathrm{W}$.

${ }^{\dagger}$ Adjustment to absolute time in sec; see text for details.

${ }^{\ddagger}$ Sec after 000400.0 GMT 18 Octaber 1989.

§Origin time at 000415.21 GMT 18 October 1989.

- No absolute time.

fAccurately estimated from time on Gilroy 1.

\# Digital instrument with memory before trigger time ( $P$ wave at $1.7 \mathrm{sec}$ ). 
Two criteria were used to select stations to include in the inversion: The observations should be close to the aftershock zone and also well distributed in azimuth. Within the epicentral region, peak ground motions are relatively independent of surface geology (Benuska, 1990). Care was also taken to avoid stations that seemed to have unusual site responses. For this reason, the CDMG station Agnew was not used, although, fortunately, it is at a similar distance and azimuth as station LEX. UCSC stations BRN, LGP, UCS, and WAH were included to provide important station coverage to the west and southwest of the epicenter. Unfortunately, the UCSC stations did not record absolute time and required additional processing to remove glitches in the raw acceleration data. The deglitching process may be inadequate at high frequencies, but it provides useful velocity recordings at the frequencies of interest in this analysis $(0.1$ to 1 $\mathrm{Hz}$ ). We address the issue of estimating absolute time for these stations in the section on the inversion method.

\section{Fault Rupture Model}

The fault parameterization and modeling procedure we employ is that described by Hartzell and Heaton (1983) in their study of the 1979 Imperial Valley earthquake. Faulting is represented as slip on a planar surface that is discretized into a number of subfaults. The ground motion at a given station can be represented as a linear sum of subfault contributions, each appropriately delayed in time to simulate fault rupture. Formal inversion procedures are then used to deduce the slip distribution on these subfaults that minimizes the difference between the observed and synthetic waveforms.

In the study, we represent the Loma Prieta rupture area as a $40-\mathrm{km}$-long plane striking $\mathrm{N} 128^{\circ} \mathrm{E}$ and dipping $70^{\circ}$ toward the southwest. The fault extends from a depth of $1.5 \mathrm{~km}$ to $20.3 \mathrm{~km}$, giving a downdip width of $20 \mathrm{~km}$ (Fig. 3). We chose the overall dimensions of the fault to enclose the region of major aftershock activity (Dietz and Ellsworth, 1990), although there has been some discussion about the possibility of vertical strike-slip faulting on a second plane extending past the southern end of our inferred rupture area. This possibility is discussed later. The strike and dip values of our fault plane were

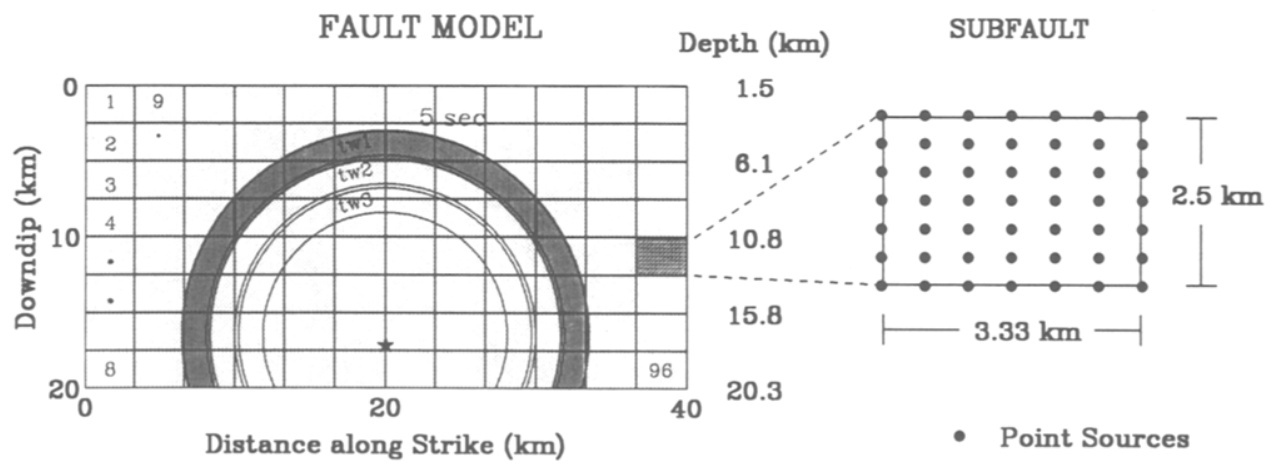

FIG. 3. Northwest-southeast cross section of the fault rupture model along the fault plane indicating subfault layout. The subfault enlargement displays the distribution of point sources for each subfault. The largest circle radiating outward from the hypocenter (star) represents the progression of the rupture front after 5 sec. Smaller concentric circles delimit the (slightly overlapping) fault regions slipping in time windows 1 (tw1-shaded), 2 (tw2), and 3 (tw3). 
chosen from the broadband inversion results of Kanamori and Satake (1990). This fault plane is also consistent with the aftershock lineation (Dietz and Ellsworth, 1990), the focal mechanism determined from first-motion data (Oppenheimer, 1990), and the $P$ and $S H$ teleseismic waveforms shown in Figure 4. Slight discrepancies in strike and dip would have little effect on our model results and conclusions.

The fault-plane geometry chosen for this study differs somewhat from the geometry used by Lisowski et al. (1990) to model the geodetic data. Although

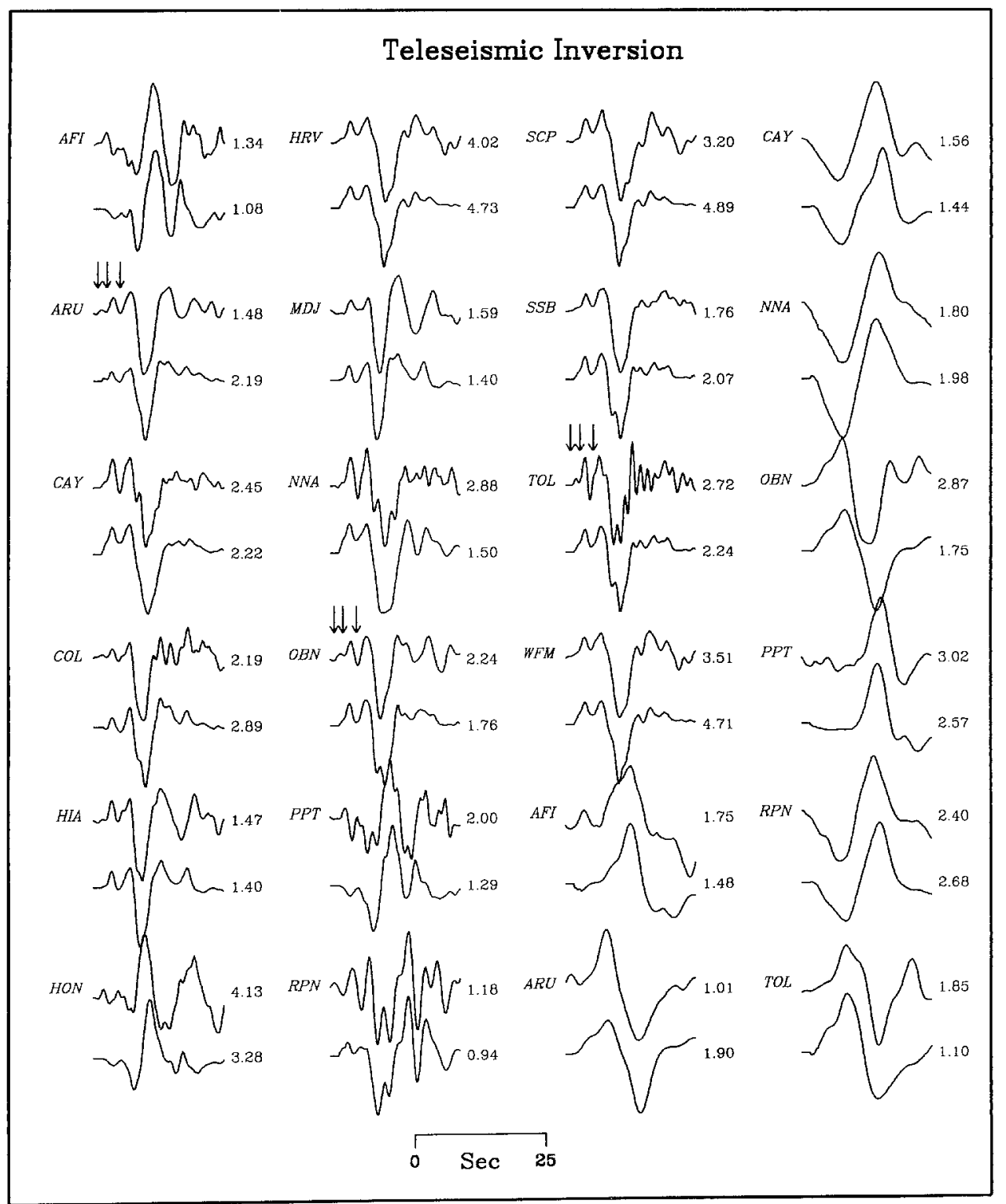

Fig. 4. Comparison of observed (top) and synthetic (bottom) teleseismic records. The first 16 stations are $P$ waves, and the last eight stations are $S H$ waves. Amplitudes are in $10^{-1}$ microns/sec. 
they also used a dip of $70^{\circ}$, they found that a strike of $\mathrm{N} 136^{\circ} \mathrm{E}\left(8^{\circ}\right.$ more northerly than ours) was necessary to explain their data. Furthermore, their fault plane was shifted about $2 \mathrm{~km}$ westward of our assumed plane, which was chosen to coincide with the aftershock distribution. In general, the geodetic data are more sensitive to fault geometry than the waveform data but as not as powerful in resolving details of the slip distribution. Differences in the fault geometry inferred from the static offsets, when compared with waveform studies, may reflect complexities in the nature of the rupture, such as a nonplanar fault or multiple fault rupture. These complexities are not considered in this study.

Our fault area is discretized into 12 subfault elements along strike and eight elements downdip, giving each subfault a length of $2.5 \mathrm{~km}$ and a vertical width of $3.33 \mathrm{~km}$ (Fig. 3). This subfault area is a compromise chosen to give sufficient freedom to allow rupture variations necessary to successfully model the ground motions and yet minimize computational time. The computation time for the inversion is proportional to the cube of the number of unknown parameters, in this case the number of subfault slip values to be determined.

\section{Synthetic Green's Functions}

The synthetic ground motion contribution for each subfault is computed using the Green's function summation and interpolation method of Heaton (1982) and is only briefly summarized here. The subfault motions are obtained by summing the responses of a number of point sources distributed over the subfault. We sum 49 equally spaced point sources (see Fig. 3) appropriately lagged in time to include the travel-time difference due to the varying source positions and to simulate the propagation of the rupture front across each subfault. In all, 4704 point sources are summed to construct the teleseismic and strong-motion synthetics at each station for both a pure strike-slip and a pure dip-slip mechanism. Thus, each subfault includes the effects of directivity.

The point source responses, or Green's functions, for teleseismic $P$ or $S H$ body-wave synthetic seismograms are computed using the generalized ray method (Langston and Helmberger, 1975). We include the responses of all rays up to two internal reflections in a layered velocity model, including free surface and internal phase conversions. A $Q$ operator (Futterman, 1962) is applied with the attenuation time constant $t^{*}$ equal to 1 and $4 \mathrm{sec}$ for $P$ and $S H$ waves, respectively.

The point source responses for the strong motions are computed for a layered velocity model with the discrete wavenumber/finite element (DWFE) methodology of Olson et al. (1984) for frequencies up to $3.5 \mathrm{~Hz}$. In practice, we calculate a master set of synthetics for increments in depth from 1.5 to $20.3 \mathrm{~km}$ and for ranges between 0 and $75 \mathrm{~km}$, to allow for the closest and furthest possible subfault-station combinations. Then for each subfault-station pair, the required subfault response is derived by the summation of 49 point source responses obtained by the linear interpolation of the closest Green's functions available in the master set. The linear interpolation of adjacent Green's functions is performed by aligning the waveforms according to their shear-wave travel times. Subfault contributions from both a pure dip-slip and pure right-lateral-slip mechanism are computed using the assumed fault geometry. The relative weights of these fundamental mechanisms, as well as the amount of slip on each subfault, are determined in the inversion process described later. 


\section{Velocity Model}

The velocity model used to compute the DWFE Green's functions is given in Table 3 . The $P$-wave velocities were obtained by averaging the two velocity depth profiles in this region given by Dietz and Ellsworth (1990) for regions northeast and southwest of the San Andreas fault. We have also added a thin, slower layer to this model to better approximate elastic properties just beneath the strong-motion stations. $S$-wave velocities were obtained by assuming that the structure is a Poisson solid.

The velocity model used to compute the teleseismic Green's functions is a five-layer approximation of the velocity model given in Table 3 . Heaton and Heaton (1989) discuss difficulties that arise when seismic moments derived from different velocity models are compared. Fortunately, the seismic velocities are nearly constant for both the teleseismic and strong-motion velocity models in the depth range from 7 to $18 \mathrm{~km}$ (the region of highest slip). This favorable coincidence means that a simple comparison of seismic moments derived from teleseismic and strong-motion inversions is approximately valid.

\section{Source Time Function and Rupture Velocity}

The subfault synthetics are convolved with a dislocation time history, which we represent by the integral of an isosceles triangle with a duration of $0.7 \mathrm{sec}$. This slip function was chosen based on a comparison of the synthetic velocity pulse width for a single subfault with the shortest duration velocity pulse width observed, as well as on prior experience with this inversion method (Heaton, 1990). As Hartzell and Mendoza (1991) point out, resolution of the slip function is difficult, although we are required by the strong motion recordings to employ a relatively short $(<0.8 \mathrm{sec})$ duration.

The rupture velocity is assumed to be a constant $2.7 \mathrm{~km} / \mathrm{sec}$, or $75 \%$ of the shear-wave velocity in the main part of the source region (Table 3). Many observations, including the absence of tectonic surface slip (U.S. Geological Survey Staff, 1990), indicate that little dislocation occurred above a depth of about $4 \mathrm{~km}$. The position of the rupture front $5 \mathrm{sec}$ after the nucleation time is shown in Figure 3.

Some flexibility in the rupture velocity and slip time history is obtained by introducing time windows (Hartzell and Heaton, 1983). Each subfault is

TABLE 3

Loma Prieta Velocity Structure

\begin{tabular}{ccccc}
\hline$V_{p}$ & $V_{s}$ & $\rho$ & $h$ & $z$ \\
\hline 1.73 & 1.00 & 1.50 & 0.1 & .1 \\
3.38 & 1.95 & 1.55 & 0.4 & .5 \\
4.29 & 2.48 & 1.85 & 0.5 & 1.0 \\
4.80 & 2.77 & 2.05 & 2.0 & 3.0 \\
5.37 & 3.10 & 2.26 & 2.0 & 5.0 \\
5.74 & 3.31 & 2.45 & 2.0 & 7.0 \\
6.15 & 3.55 & 2.58 & 2.0 & 9.0 \\
6.25 & 3.61 & 2.62 & 4.0 & 13.0 \\
6.27 & 3.62 & 2.63 & 5.0 & 18.0 \\
6.67 & 3.85 & 2.77 & 7.0 & 25.0 \\
8.00 & 4.62 & 3.28 & 50. & \\
\hline
\end{tabular}


allowed to slip in any of three identical 0.7-sec time windows following the passage of the rupture front thereby allowing for the possibility of a longer slip duration or a locally slower rupture velocity. Hartzell and Mendoza (1991) obtained very similar dislocation models for the 1978 Tabas, Iran, earthquake ( $M_{s}=7.4$ ) using both a linear inversion parameterizing slip with three time windows (as is done here) and also using a nonlinear iterative inversion, which allows a single rupture at each point on the fault, but which allows the rupture velocity to vary.

In this study, each time window is separated by $0.6 \mathrm{sec}$, allowing a small overlap of the 0.7 -sec duration subfault source-time function. Thus, as depicted in Figure 3, the region of the fault that is allowed to slip 5 sec (for example) after the nucleation of rupture is within concentric bands occupied by the three time windows. As will be discussed later, the relative slip amounts in each time window indicate that there is little evidence for significant rupture velocity variation for this earthquake.

\section{InVERSION Method}

A constrained, damped, linear, least-squares inversion procedure is used to obtain the subfault dislocation values that give the best fit to the strong-motion velocity waveforms. The inversion is stabilized by requiring that the slip is everywhere positive and that the difference in dislocation between adjacent subfaults (during each time window) as well as the total moment is minimized. These constraints have been previously discussed by Hartzell and Heaton (1983).

Both the strong-motion observations and subfault synthetic seismograms are bandpass filtered from 0.1 to $1.0 \mathrm{~Hz}$ with a zero-phase Butterworth filter and are resampled at a uniform time step of 10 samples per sec. The teleseismic data were similarly filtered from 0.02 to $1.0 \mathrm{~Hz}$. The upper frequency limit is imposed by the nature of the strong-motion recordings. In general, there is more coherence in the waveforms at periods greater than $1 \mathrm{sec}$ than at higher frequencies. Originally, the strong-motion data were low-pass filtered at $3 \mathrm{~Hz}$, but we found indications of significant complication apparently caused by local site response effects. We modeled the first $25 \mathrm{sec}$ of the record for teleseismic data and between 14 to $22 \mathrm{sec}$ of the strong-motion records (depending on the individual record).

\section{Timing}

The initial alignment in time of the observed and synthetic seismograms is a critical issue in modeling waveform data in order to determine the temporal and spatial distribution of slip on the fault plane. In this type of study, two approaches can be taken. One approach (commonly used for teleseismic waveform inversions) is to time-shift the synthetic waveform from a point source hypocenter until the first significant motion of the synthetic is aligned with that of the observed recording. Later source contributions (from the developing rupture process) can then be determined by modeling the remaining features of the record. This method is adequate when (1) observed first arrival time is not ambiguous and (2) it is clear that the initial arrival is actually from the locally determined hypocenter (including the origin time). Unfortunately, the first arrivals (observed on local seismic networks) for waves from the hypocenter may be too small to be seen teleseismically or on strong-motion recordings. 
These first arrivals are, however, used to determine the hypocenter and origin time of the earthquake. Serious problems arise if it is erroneously assumed that the first arrival on a teleseismic or strong-motion record is from the hypocenter determined from local seismic network data. Hartzell and Heaton (1983) show how this is a serious problem when interpreting the 1979 Imperial Valley, California, earthquake.

In the second approach, all correlations are done in absolute time, with appropriate time delays to accommodate errors introduced by inadequacies of the assumed velocity model. At teleseismic distances, these delays can be substantial, so master event techniques must be employed (e.g., Hartzell and Heaton, 1983). For the local strong-motion data, the use of absolute time is preferable if it is known for a majority of the recordings. We use this second approach in this strong-motion modeling study.

When the trigger time is available (see Table 2), synthetic and observed waveforms are aligned in absolute time. Slight adjustments are also made to allow for variations in travel time not predicted by the assumed 1-D velocity structure (Table 2, station delays). While this provides an approximate static station delay, it will not improve timing errors introduced by lateral variations encountered by subfault to station travel paths that vary significantly along the fault. This issue can be addressed later with the analysis of aftershock recordings at strong-motion sites when these data are made available.

For stations without absolute time, synthetic and observed waveforms are aligned based on the assumption that the initial $P$ wave triggers the instrument. The stations with timing are weighted heavily in the inversion, and those without are downweighted, effectively removing them from the inversion. Using the preliminary inversion results, synthetic waveforms are calculated for those stations without timing, and new time estimates are obtained by comparing synthetic and observed waveforms. At some stations (UCS and WAH), the forward prediction was insufficient to estimate the timing, and these stations were not given significant weighting in subsequent inversions. We did, however, continue to compute waveforms for these for comparison with the observed waveforms and for later analysis.

\section{Teleseismic Modeling}

\section{Previous Studies and Preliminary Analysis}

To date, several broadband teleseismic studies of the Loma Prieta earthquake have been made, and their conclusions are partially summarized in Table 4 . As pointed out by Choy and Boatwright (1990), three distinct arrivals can be recognized on most of the broadband teleseismic recording. Choy and Boatwright (1990) associate each of the three separate pulses with separate subevents. These can be seen on the observed velocity recordings in Figure 4 (top traces) and are marked with arrows at selected stations. The first arrival is quite small but can be seen on the $P$-wave records, about $1 \mathrm{sec}$ into the trace, at stations ARU, OBN, and TOL. The first subevent is at the threshold of resolution for waveform modeling for the teleseismic data.

In general, these teleseimic models describe this earthquake as a simple two point source combination representing two later, dominant subevents. The seismic moments determined in these broadband studies range from 2.0 to $3.0 \times 10^{26}$ dyne-cm. There is also a large variation in the ratio of the relative 
TABLE 4

Loma Prieta Earthquake Teleseismic Studies

\begin{tabular}{|c|c|c|c|c|c|c|}
\hline \multirow[b]{2}{*}{ Author(s) } & \multicolumn{3}{|c|}{ Mechanism } & \multirow{2}{*}{$\begin{array}{l}M_{0}(\text { dyne-cm) } \\
\quad \times 10 * 26\end{array}$} & \multirow[b]{2}{*}{ Data Used } & \multirow[b]{2}{*}{ Centroid Location ${ }^{*}$} \\
\hline & Strike & Dip & Rake & & & \\
\hline $\begin{array}{l}\text { Barker and } \\
\text { Salzberg (1990) } \\
\text { Choy and }\end{array}$ & 130 & 73 & 146 & 2.8 & $\mathrm{LB}, \mathrm{BB}$ & $\begin{array}{l}\mathrm{D} 1=18 \mathrm{~km}, \mathrm{D} 2=14 \mathrm{~km}, \\
\mathrm{Mo} 1=27 \%, \mathrm{M} 02=73 \%\end{array}$ \\
\hline Boatwright (1990) & 130 & 65 & 140 & 2.2 & BB $15 P 8 S H$ & $\begin{array}{l}\mathrm{D} 1=16 \mathrm{~km}, \mathrm{D} 2=12 \mathrm{~km}, \\
\mathrm{Mo} 1=34 \%, \mathrm{Mo}_{2}=50 \%\end{array}$ \\
\hline Kanamori and & 128 & 70 & 138 & 3.0 & BB $8 P 8 S H$ & $\mathrm{D}=15 \mathrm{~km}$ \\
\hline Satake (1990) & 128 & 70 & 137 & 2.5 & Surface waves & \\
\hline $\begin{array}{l}\text { Langston et al } \\
(1990)\end{array}$ & 130 & 56 & 158 & 2.3 & BB $8 P 6 S H$ & $\mathrm{D}=8 \mathrm{~km}$ \\
\hline Nábělek (1990) & 128 & 63 & 128 & 3.0 & BB & $\mathrm{D}=7$ to $12 \mathrm{~km}$ \\
\hline Romanowicz and & 128 & 66 & 138 & 2.2 & BB $9 P 6 S H$ & $\mathrm{D}=10 \mathrm{~km}$ \\
\hline Lyon-Caen (1990) & 127 & 66 & 132 & 3.3 & Rayleigh & \\
\hline $\begin{array}{l}\text { Ruff and Tichlaar } \\
(1990)\end{array}$ & 138 & 76 & 120 & 2.0 & BB $8 P 2 S H$ & $\mathrm{D}=10 \mathrm{~km}$ \\
\hline Wallace (1990) & 132 & 69 & 134 & 2.1 & $\mathrm{BB}$ & $\begin{array}{l}\mathrm{Z} 1=17 \mathrm{~km}, \mathrm{Z2}=11 \mathrm{~km} \\
\mathrm{Mo} 1=20 \%, \mathrm{Mo} 2=80 \%\end{array}$ \\
\hline $\begin{array}{l}\text { Zhang and } \\
\text { Lay (1990) }\end{array}$ & 130 & 70 & 135 & 3.4 & Rayleigh & \\
\hline
\end{tabular}

${ }^{*}$ For best point source of centroid one, value is given; if more than one point source or subevent was described, depths and relative moments are given as D1, Mo1, D2, Mo2, etc.

moments for subevent 3 compared with subevent 2 , from about 1.5:1 up to about 4:1 (Table 4), depending on the assumptions of the individual researcher. In addition, there is a wide spread in the estimate of the best point source depths for the second and third subevents, or for a single estimate of the centroid location. This suggests that the rupture, although over a finite area, was not extensive enough to be easily resolved teleseismically (i.e., less than about 35 $\mathrm{km}$ ), consistent with the limited extend of rupture inferred from the aftershock distribution alone (Dietz and Ellsworth, 1990).

When teleseismic velocity waveforms are integrated into displacements, it becomes difficult to distinguish arrivals from individual subevents. In particular, the arrival from the second subevent appears as a subtle inflection in the large pulse from the third subevent. Although very similar results were obtained by modeling the teleseismic displacement waveforms, we find it easier to compare synthetic and observed velocity waveforms.

\section{Inversion Results}

The spatial distribution of slip obtained from inversion of only the teleseismic data is shown in Figure 5. The slip contours are in intervals of $50 \mathrm{~cm}$, and increased shading indicates larger slip as displayed in the legend shown at the right of each diagram. We use a large contour interval to emphasize robust features in the model and to minimize the importance of smaller details. The dislocations shown represent the combined slip for the three time windows previously mentioned.

Our teleseismic model has a seismic moment of $2.8 \times 10^{26}$ dyne-cm. Comparison of the observed teleseismic records (top) and the synthetic seismograms (bottom) predicted by the teleseismic dislocation model are shown in Figure 4. 

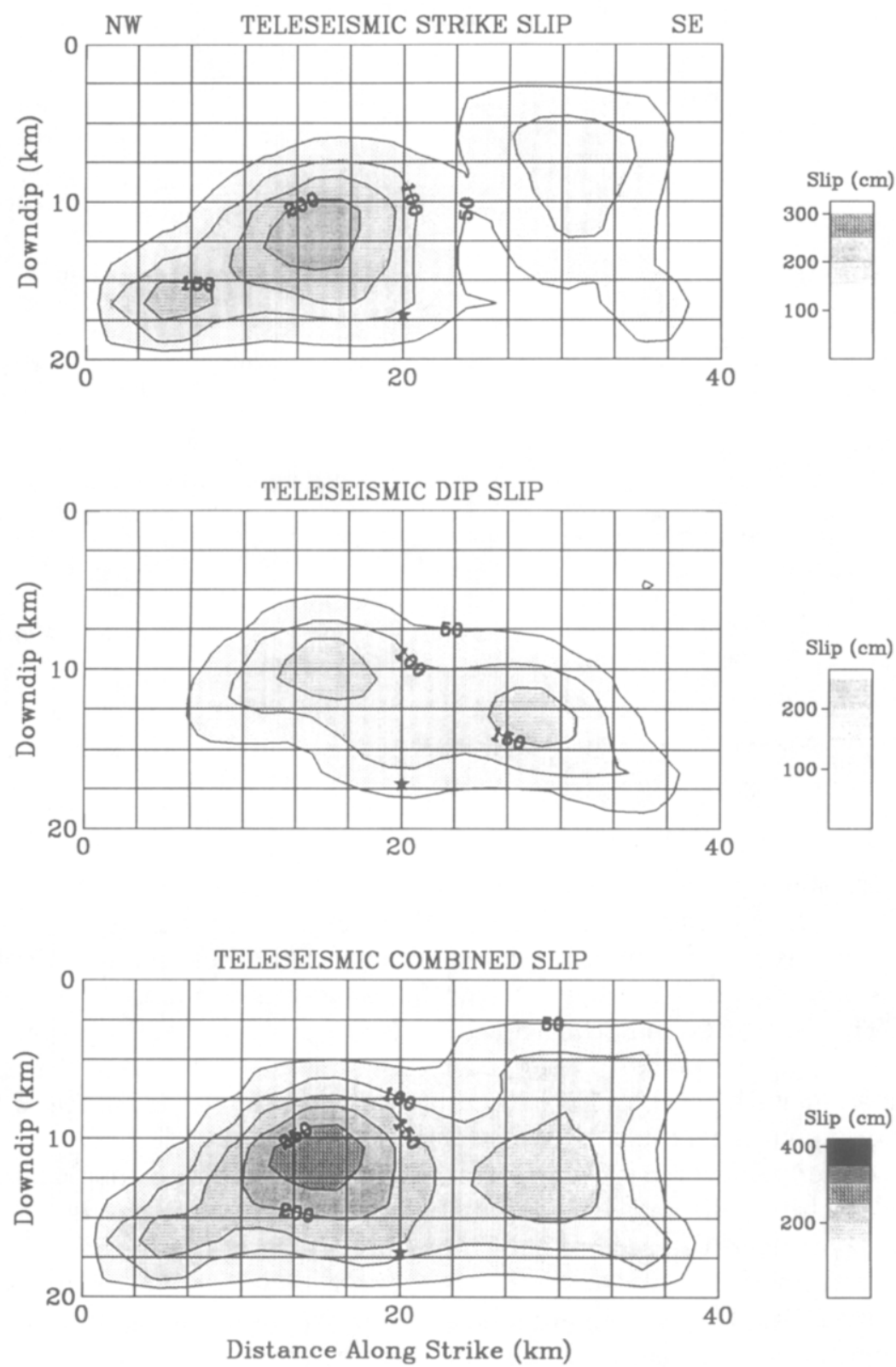

FIg. 5. Northwest-southeast cross section of the fault model showing contours of dislocation for strike-slip (top), dip-slip (middle), and oblique-slip (bottom) resulting from the teleseismic inversion. Contour interval is $50 \mathrm{~cm}$. Shading values indicating slip in $\mathrm{cm}$ are given by the scale to the right of each diagram.

The amplitudes are given in microns per sec. The main features of this model are (1) a two-lobed bilateral rupture with a slightly larger slip to the northwest, (2) the largest slips concentrated at a depth of $11 \mathrm{~km}$ for the northwestern patch and slightly deeper for the southeastern patch, and (3) little slip in the region updip from the hypocenter.

Directivity controls the waveform and amplitude only when the rupture front progresses at at velocity comparable to the phase of interest. For this reason, 
the teleseismic body waves, all having steep takeoff angles, are limited in their ability to resolve rupture directivity along strike but are quite sensitive to up or downdip rupture propagation. The lack of vertical directivity in our solution is apparent. Since the teleseismic data do not allow significant slip updip or downdip from the hypocenter, the majority of slip must occur along strike from the hypocenter. Bilateral rupture is indicated by the timing of the second and third arrivals and by the absence of significant azimuthal arrival time differences between the two dominant arrivals. As will be discussed in the following section, this model explains many features observed in the local strong-motion data.

\section{Strong-Motion Modeling}

\section{Preliminary Analysis}

Peak Motions. Inspection of the pattern of near-source peak ground velocities (Fig. 2) reveals that the largest motions occurred at stations located near the northwestern (LEX, LGP, SAR) and southeastern (HOL, WAT, GHB) ends of the aftershock zones. Tendency for large motions at both ends of the aftershock zone, particularly to the northwest, can be seen in the Modified Mercalli intensity VIII isoseismal map shown in Figure 2c. This contrasts with the relatively low amplitudes recorded at COR, which is directly updip from the hypocenter, a location at which we expect to see strong directivity from a rupture propagating updip.

Additional evidence for bilateral rupture can be seen in the timing and similarity of the velocity recordings at GGC and SAR (Fig. 6, middle 6 traces). As seen in Figure 2, these stations are symmetrically located about the fault plane and are at nearly the same epicentral distance. Polarities for the radial and vertical components for station SAR have been reversed to correct for the change in sign of the $P-S V$ radiation pattern in order to enhance the comparison. Although absolute time was not available for SAR, its timing was estimated by noting the similarity of the $S$ waveform with LEX (Fig. 2) and then correcting for the additional shear-wave propagation time from LEX to SAR. The timing and waveforms of the main arrivals at GGC and SAR are similar, although they are slightly earlier at GGC than at SAR. However, the peak amplitudes are considerably larger at SAR (Fig. 2). These observations demand a nearly symmetric, bilateral rupture with considerably more $1-\mathrm{Hz}$ energy radiated towards the northwest. A single asperity centered at or above the hypocenter could also explain the symmetry in timing and waveform at these stations, but this is inconsistent with the small velocity amplitudes observed at stations located near the center of the aftershock region (BRN, CAP, COR, UCS, and WAH) that should be otherwise enhanced in amplitude by a slip concentra tion in the center of the fault. Further, a central asperity cannot easily account for the larger amplitude velocities observed toward the northwest and smaller velocities observed toward the southeast. These observations agree with the main features found from the inversion of the teleseismic data.

\section{Trigger Times and Rupture Initiation}

The hypocentral parameters we use are from Dietz and Ellsworth (1990) and are given in Table 2. In Figure 7, we compare the theoretical $P$-wave travel times for each station with the corresponding trigger times. Because only vertical motions trigger the strong-motion accelerometers, it is likely that they 


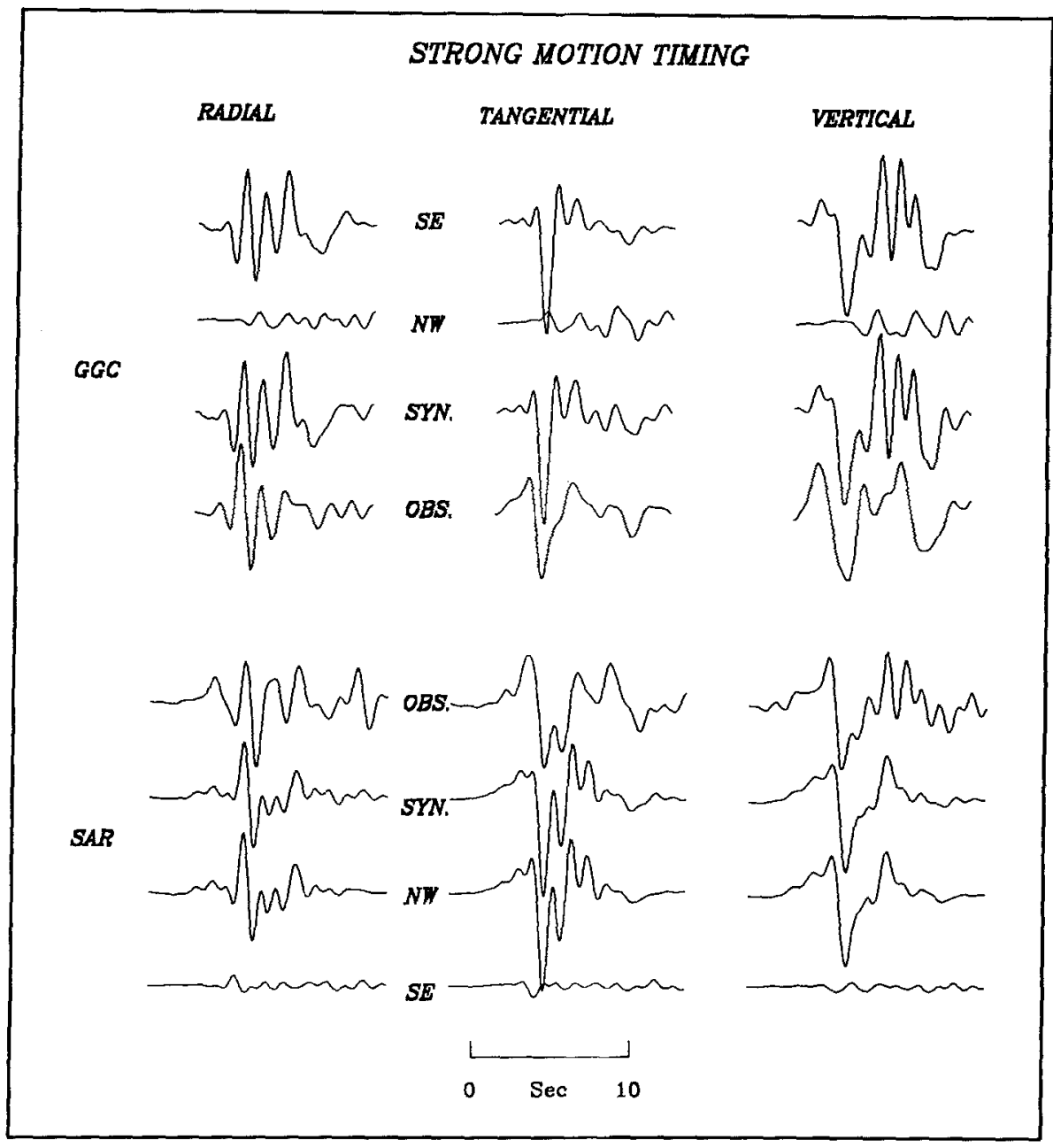

FIG. 6. Comparison of velocity recordings for stations GGC and SAR aligned vertically in absolute time. Polarities of the radial and vertical components for station SAR have been reversed to enhance the comparison. The synthetic contribution from the northwest (NW) and southeast (SE) halves of the fault model are shown in addition to the complete synthetic velocity. For each component, the records are on the same scale and normalized to the peak value. The observed records are adjacent to each other in the center of the figure.

were triggered by $P$-wave arrivals. However, the accelerometers were actually triggered about $2 \mathrm{sec}$ later than the $P$-wave arrival time predicted from the hypocentral parameters of Dietz and Ellsworth (1990). At COR, nearly directly above the hypocenter, the observed trigger time is about $1.8 \mathrm{sec}$ after the $P$-wave arrival time predicted using the velocity model shown in Table 3 . Other stations show similar delays. We examine this delay in Figure 8 by displaying the waveforms and timing of data from a variety of instrument types. The lowand high-gain vertical components at CALNET station BSR are shown at the top of the figure, followed by teleseismic station TOL, strong-motion station SAR, and station SAO, a Berkeley broadband instrument. These waveforms are aligned in absolute time, with the exception of TOL, which is aligned according to our interpretation of the rupture initiation. That is, the simplest explanation for this 2-sec delay is that a foreshock, whose magnitude was too small (less 


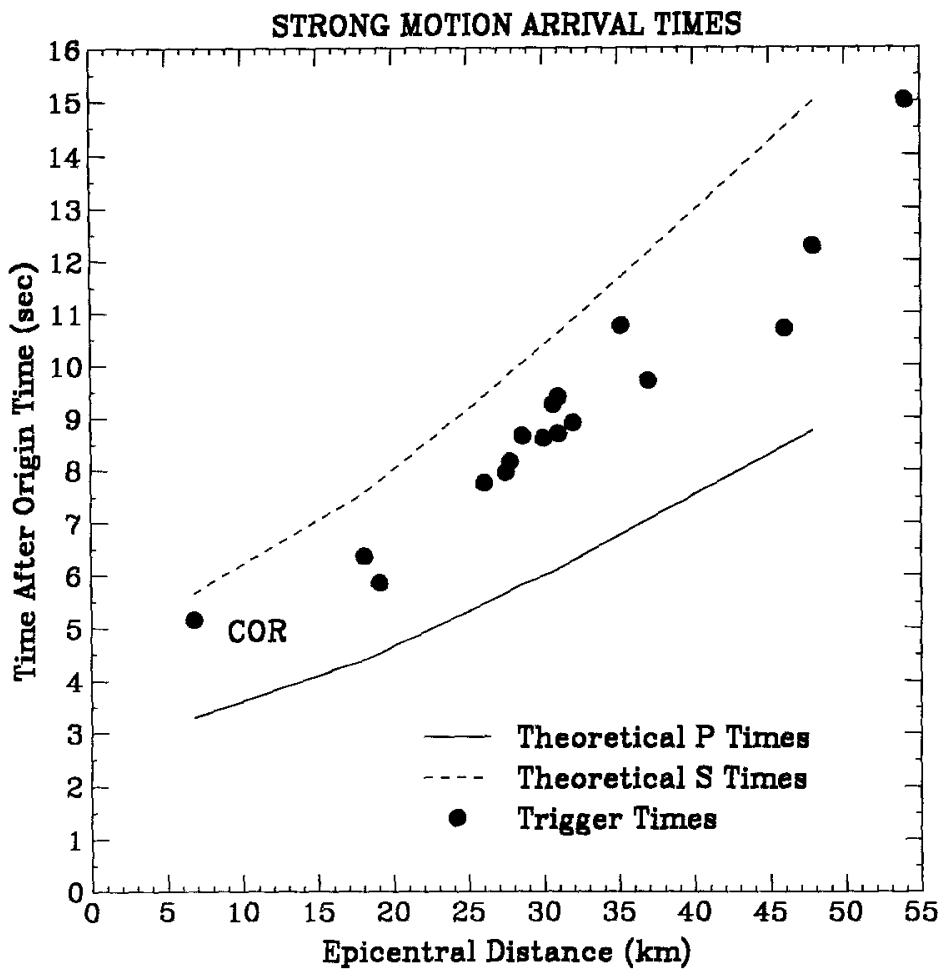

FIG. 7. Comparison of strong-motion trigger time (stars) with the predicted $P$-wave arrival times (solid line) for the velocity model given in Table 3 based on the published hypocentral time (00 04 15.21 GMT). The predicted $S$-wave arrival time is given for reference.

than about 5) to trigger the strong-motion instruments, occurred about 2 sec before the main part of the rupture, and it is this foreshock that was located as the hypocenter using the high-gain regional network data. However, we suggest that the initial 2 sec represents the initial stage of rupture, perhaps a smooth, slow growth episode (Wald et al., 1991). As shown in Figure 8, the initial stage of rupture clipped the nearby high-gain station BSR but shows a long-period component as seen in the low-gain component. The low-gain component clipped after about $1.6 \mathrm{sec}$. It is after this time that (1) the first teleseismic energy becomes visible, (2) the strong-motion stations, begin to trigger, and (3) the local broadband stations change character from a long-period one-sided waveform and dramatically clip. These observations can be interpretated as a slow rupture nucleation that generated insufficient long-period energy to be seen teleseimically and insufficient high-frequency radiation to trigger the strong-motion instruments.

The observation that led to the discovery of this timing problem was the initial inversion of the strong-motion waveforms using absolute time. The resulting slip distribution model required a two-lobed pattern similar to the teleseismic results, but the centers of these lobes were forced toward the sides of the fault. The slip distribution was inconsistent with that derived from the teleseismic data and also with the source region suggested by the aftershock patter (Dietz and Ellsworth, 1990). Furthermore, it generated inferior fits to the strong-motion data. 


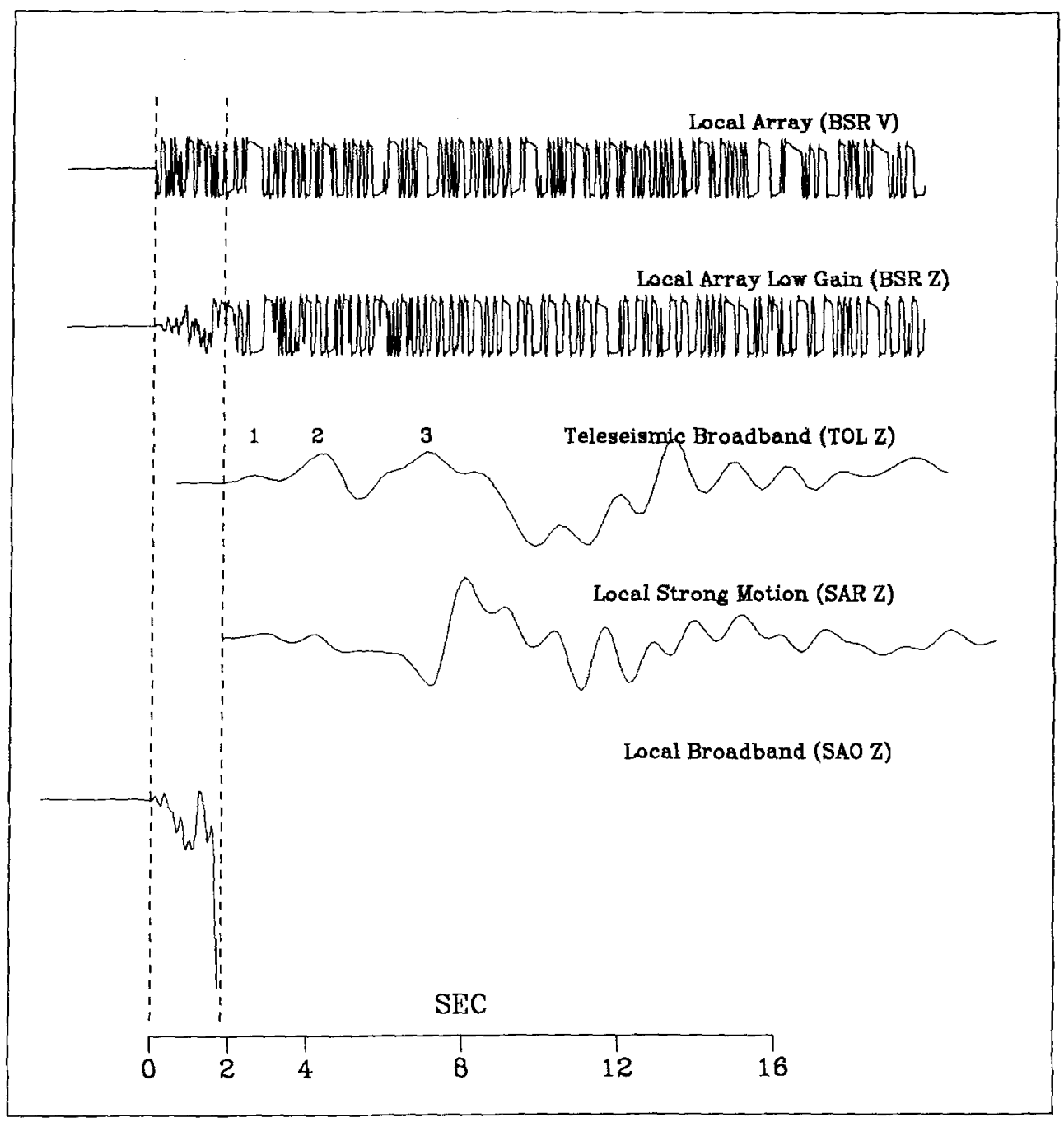

FIG. 8. Comparison of waveforms indicating delay to main part of the rupture. Data are aligned in absolute time with the exception of the teleseismic record TOL (see text for details). Dashed lines correspond to times of 0.0 and 1.8 sec. Arrivals 1,2 , and 3 labeled on the TOL record refer to arrivals shown in Figure 4.

Thus, failure to account for this delay can seriously affect source models based on waveform inversion using absolute timing. In particular, the modeled rupture front would already have progressed $5 \mathrm{~km}$ away from the hypocenter during this 2-sec interval, when in fact there was probably very little rupture propagation during this period. In the modeling that follows, the strong-motion synthetic seismograms have been lagged in time by $1.8 \mathrm{sec}$. We thus chose to ignore the foreshock or rupture initiation, and we begin modeling at the time of the first significant strong ground motion. We assume that the main rupture began at or near the network hypocenter location and then allow rupture to propagate out from that location. This approach is consistent with our analysis of the teleseismic data, which also begin with the first significant rupture, since the initial rupture or foreshock was too small to be recorded teleseismically. 
It is not uncommon for the hypocenter determined from high-gain regional network data to represent a foreshock or an earlier stage of rupture not observed on other data sets. Wald et al. (1990) discuss the rupture process of the 1987 Superstition Hills earthquake and suggest that the network hypocenter represents an earlier foreshock and not the main rupture initiation. Hence, as seen on the strong-motion and teleseismic data, that event began rupturing in a different location than the hypocentral coordinates determined from the regional network data.

\section{Inversion Results}

The distribution of the slip from the inversion of only the strong motion velocities is shown in Figure 9. Comparison of the observed (top) and synthetic (bottom) strong-motion velocities are shown in Figure 10. The strong-motion rupture model is similar to that derived from the teleseismic inversion (Fig. 5). Again, slip is concentrated in two patches, one centered about $8 \mathrm{~km}$ northwest of the hypocenter at a depth of $12 \mathrm{~km}$ and with a maximum slip of $350 \mathrm{~cm}$, and the other centered about $6 \mathrm{~km}$ southeast of the hypocenter at a depth of $16 \mathrm{~km}$ with a maximum slip of $460 \mathrm{~cm}$. These parameters are summarized in Table 5 . As for the teleseismic inversion, the largest localized slip concentrations are northwest of the hypocenter.

The overall pattern of the strong-motion duration and waveform complexity can be explained by the relative position of individual stations with respect to the two lobes of concentrated slip. In Figure 11, for selected strong-motion stations, we display in map view the observed (top trace) and the synthetic (second trace) velocities along with the surface projection of the fault plane and strong-motion slip distribution. To better understand our synthetic waveforms, we also show synthetics that result from rupture on only the northwest (NW-third trace) and southeast (SE-bottom trace) halves of the fault. A similar breakdown of the synthetic ground motions for all components at stations GGC and SAR is shown in Figure 6. Velocities at stations located nearly along strike (LEX, SAR, GGC, GHB) are controlled by the nearby slip concentration and show little contribution from the further lobe. This is attributable to both the additional distance from the further lobe of concentrated slip and the favorable source directivity for stations in the direction of rupture. For this reason, the waveforms at along-strike stations are simple, large in amplitude, and short in duration. Stations in the central portion of the fault (CAP, COR) show smaller amplitudes and more waveform complexity, resulting from the lack of rupture directivity and the interference of contributions from the northwest and southeast regions of large slip. We expect these waveforms to be the most difficult to model, since the synthetic seismograms are controlled by the interference of the wave fields from two propagating rupture fronts that are diverging from one another.

\section{Joint Teleseismic and Strong-Motion Inversion}

Although there are several features that the teleseismic and strong-motion models have in common, variations in the results are apparent. The teleseismic model has considerably more strike-slip in the shallow southeast region of the fault. In addition, the overall depth of the slip concentration in the southeast half of the fault is deeper in the strong-motion model. 

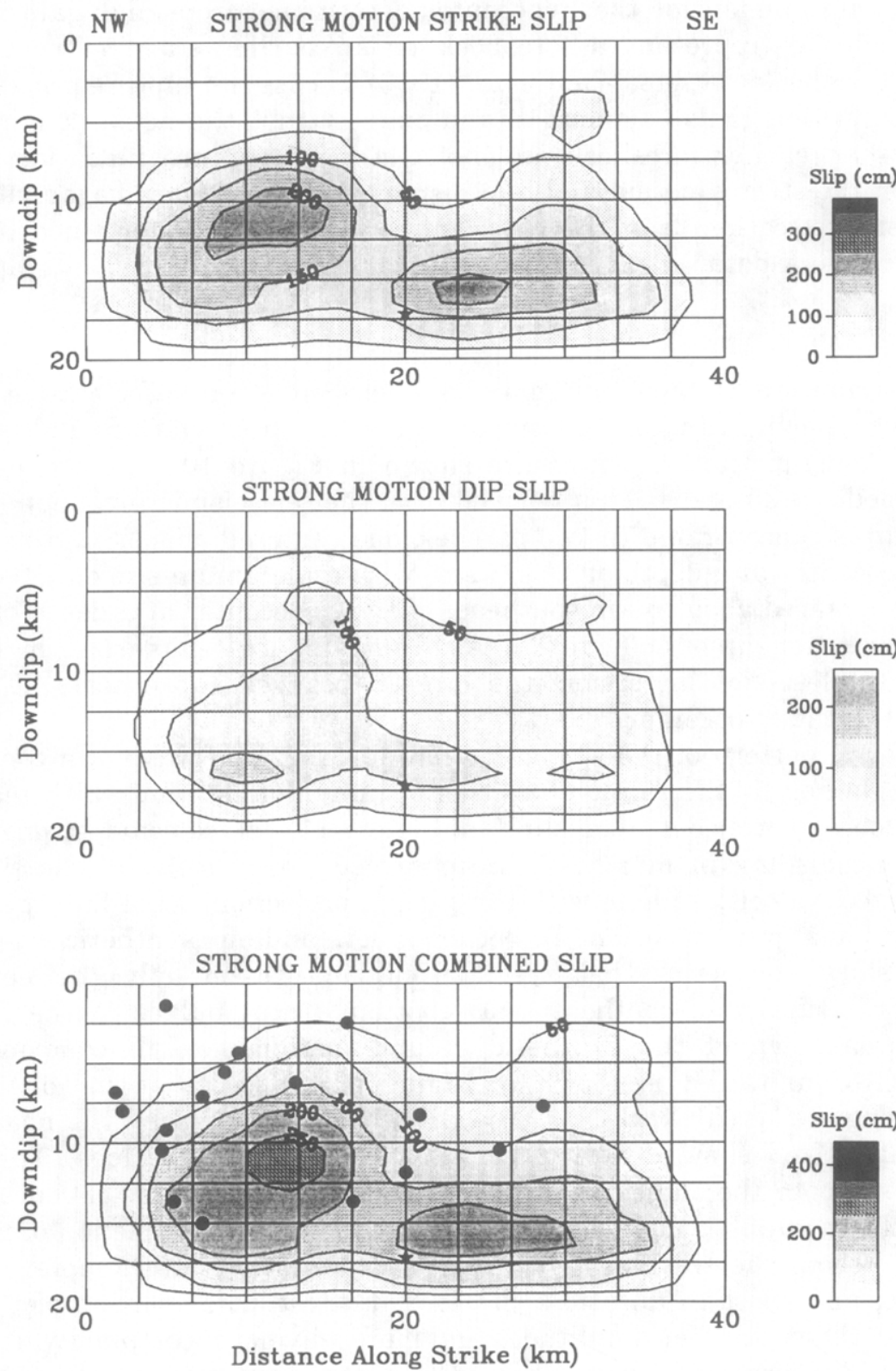

FIG. 9. Northwest-southeast cross section of the fault model showing contours of dislocation for strike-slip (top), dip-slip (middle), and oblique-slip (bottom) resulting from the strong-motion inversion. Contour interval is $50 \mathrm{~cm}$. Shading values indicating slip in $\mathrm{cm}$ are given by the scale to the right of each diagram. Aftershocks with $M>4.0$ projected onto the fault plane are represented as solid circles.

In order to test the compatibility of the teleseismic and strong-motion data and to establish a model consistent with both, we have performed a combined inversion of both data sets. There is a general tendency for teleseismic inversions to prefer solutions with numerous isolated, large slip subfaults, so significant smoothing was required to minimize the variation of slip between adjacent subfaults. The strong-motion inversion is more sensitive to higher frequency 


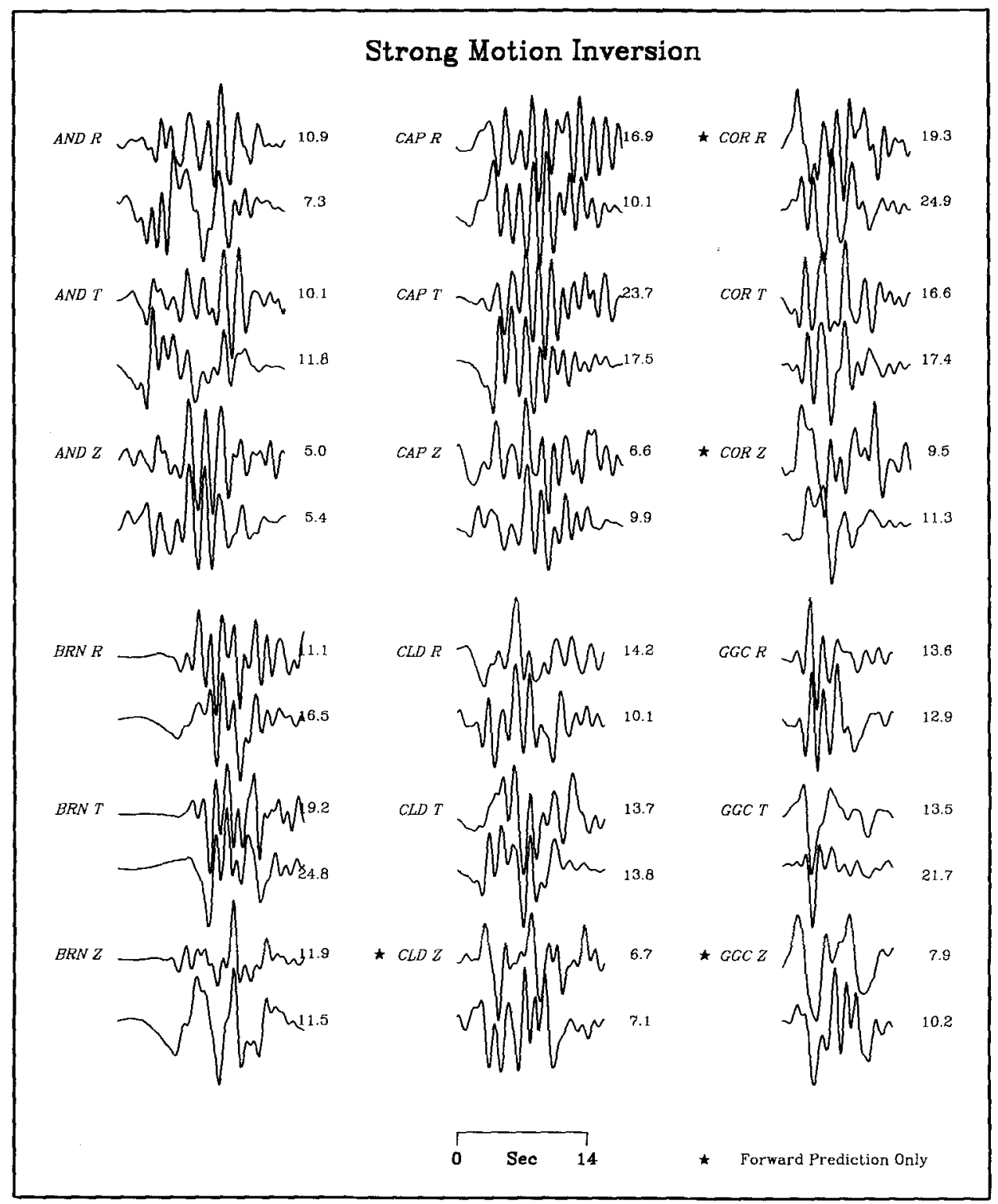

(a)

FIG. 10. Comparison of observed (top) and synthetic (bottom) strong-motion records. Amplitudes are in $\mathrm{cm} / \mathrm{sec}$.

radiation and therefore automatically limits extreme variations in rupture that produce excessive short-period radiation. Therefore, the strong-motion inversion needed little additional smoothing. In the combined inversion, we used the average of the smoothing weights used in the separate inversions. Also, because of the relatively small source dimensions, the near-source strong-motion data has more resolving power than the teleseismic data. The teleseismic data are dominated by a single velocity pulse, which is not as sensitive to subtle changes in the details of the rupture process as are the higher-frequency strong-motion 


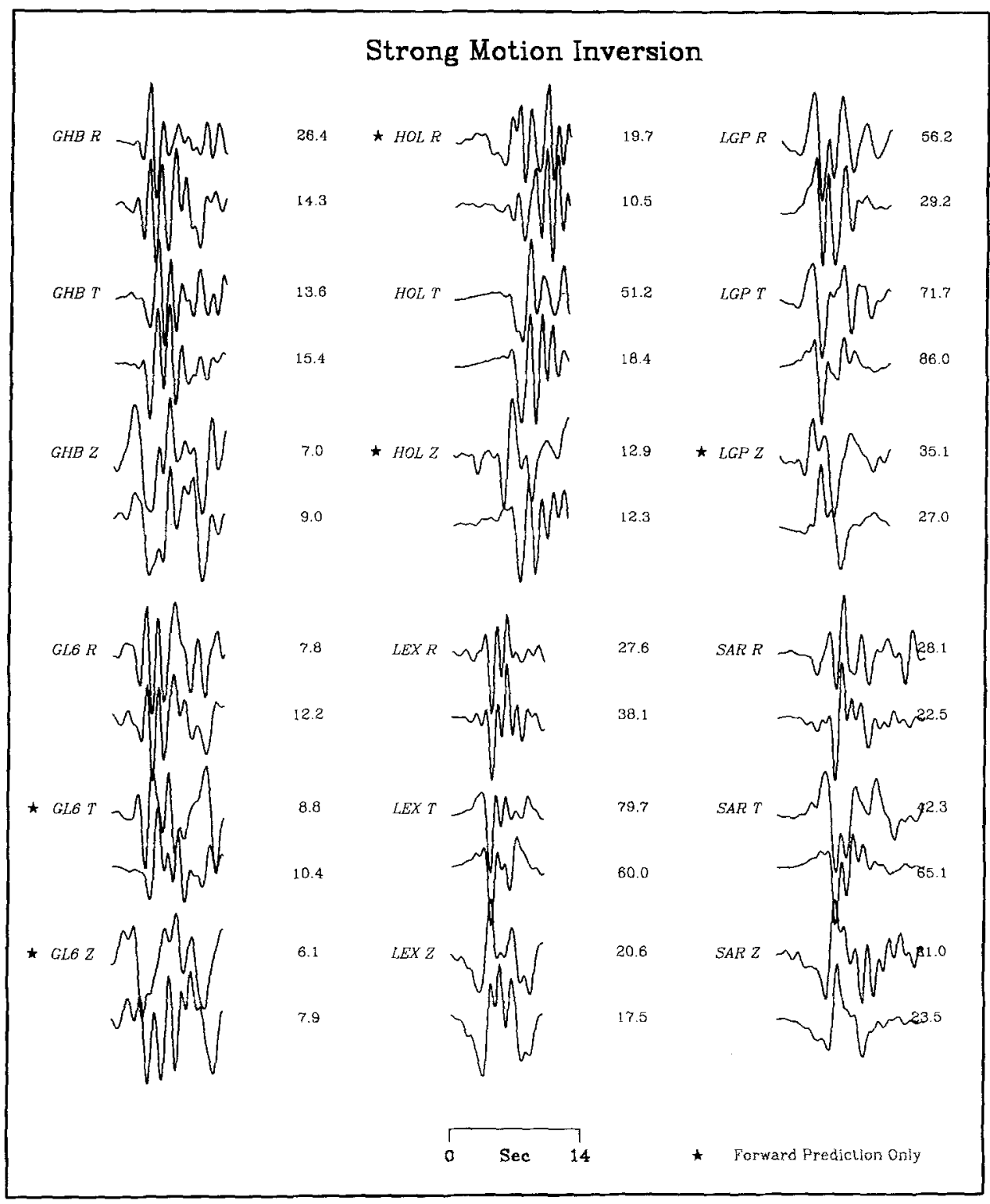

(b)

FIG, 10. (Continued)

data. Accordingly, we have chosen to weight the strong-motion results by a factor of 2 over the teleseismic data in the combined inversion.

The slip distribution resulting from the joint inversion of the strong-motion and teleseismic models (Fig. 12) is very similar to that resulting from the inversion of either the strong-motion or teleseismic waveforms. This could have been anticipated since our previous models, which were derived from these independent data sets, are so similar. The combined inversion model is our preferred model, and it represents a compromise between our two previous source models. However, in order to best satisfy both data sets, slip is more concentrated in the central portion of the northwest lobe of dislocation when 


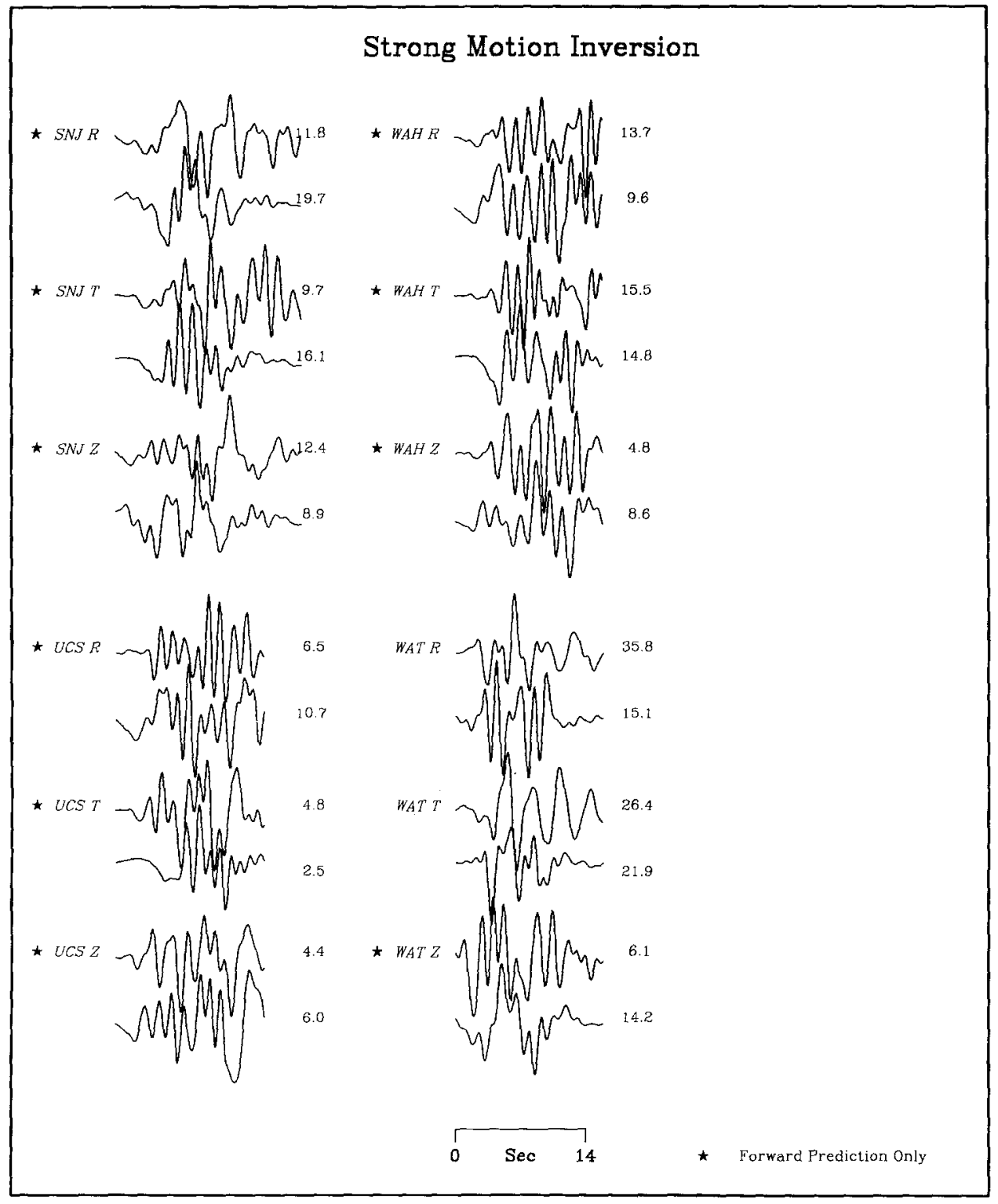

(c)

FIG. 10. (Continued)

compared with the more distributed slip seen in the previous models. There is little degradation to teleseismic waveform matches, and the strong-motion synthetic seismograms suffer only slightly from the increased smoothing constraints.

\section{Discussion}

Up to this point, we have presented our slip models using contour maps that have been spatially smoothed to deemphasize the abrupt subfault boundaries used in our inversion scheme. In order to show a more detailed comparison of 
TABLE 5

INVERSTON MODEL SUMmary

\begin{tabular}{|c|c|c|c|c|c|}
\hline Model & $\begin{array}{c}\text { Moment } \\
(\times 10 * * 26 \text { dyne-cm })\end{array}$ & $\begin{array}{l}\text { Maximum Slip } \\
\text { Slip (cm) }\end{array}$ & $\begin{array}{l}\text { Radius* } \\
(\mathrm{km})\end{array}$ & $\begin{array}{l}\text { Average } \\
\text { Slip (cm) }\end{array}$ & $\begin{array}{c}\text { Stress Drop } \\
\text { (bars) }\end{array}$ \\
\hline \multicolumn{6}{|l|}{ Strong motion } \\
\hline Northwest ${ }^{\dagger}$ & 1.9 & 350 & 7.2 & 209 & 138 \\
\hline Southeast $^{\dagger}$ & 1.2 & 460 & 6.2 & 148 & 114 \\
\hline Total & 3.1 & 460 & & 134 & 46 \\
\hline \multicolumn{6}{|l|}{ Teleseismic } \\
\hline Northwest & 2.0 & 347 & 6.3 & 210 & 155 \\
\hline Southeast & 0.8 & 420 & 5.8 & 129 & 105 \\
\hline Total & 2.8 & 420 & & 118 & 41 \\
\hline \multicolumn{6}{|c|}{$\begin{array}{l}\text { Strong motion and } \\
\text { teleseismic }\end{array}$} \\
\hline Northwest & 2.2 & 491 & 5.3 & 248 & 218 \\
\hline Southeast & 0.8 & 371 & 6.2 & 181 & 136 \\
\hline Total & 3.0 & 491 & & 141 & 49 \\
\hline
\end{tabular}

*Asperity radius for stress drop calculations (Fig. 12).

${ }^{\dagger}$ Northwest and southeast halves of the model fault.

"Stress drop of asperities in northwest and southeast halves of the fault shade in Figure 12 (see text for details).

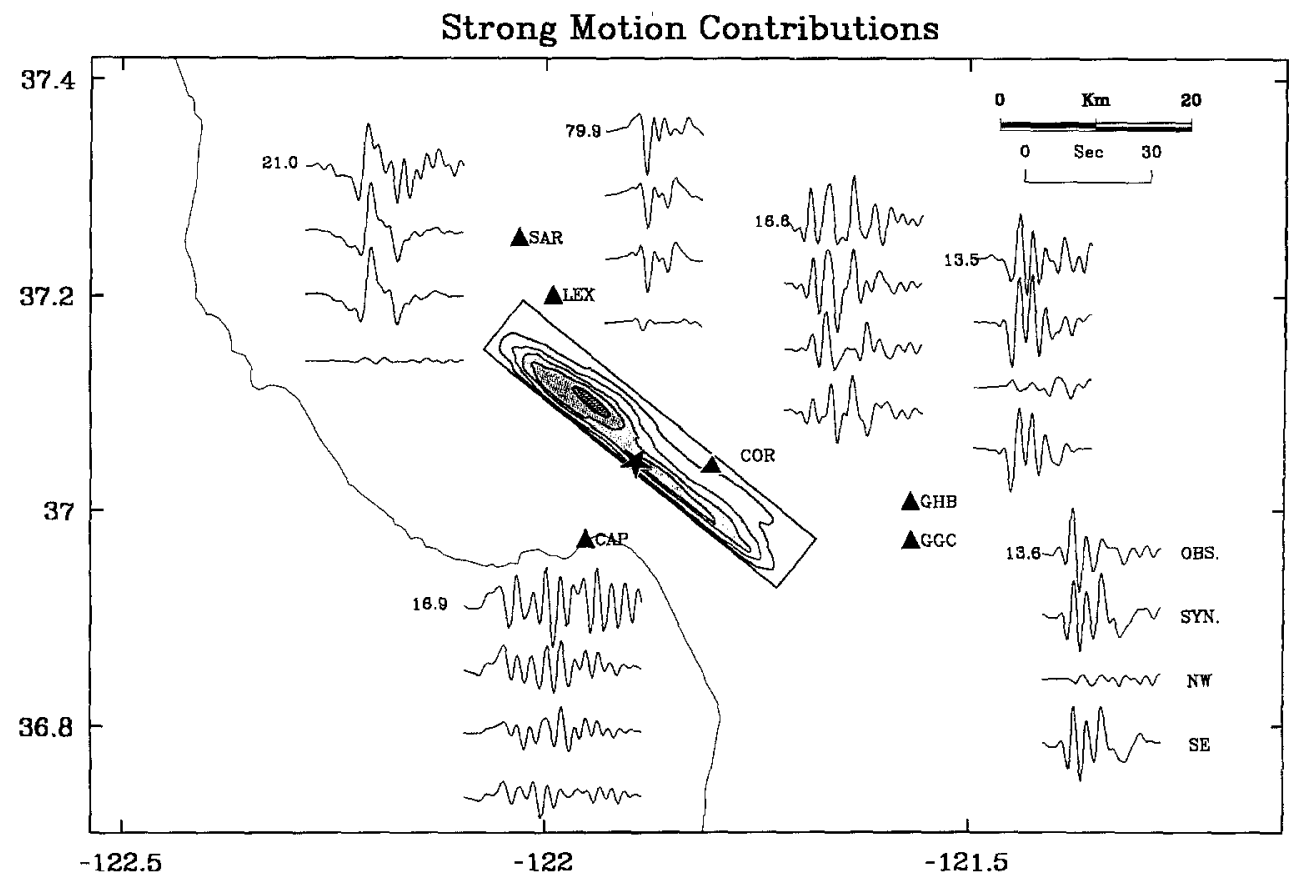

FrG. 11. Display of strong-motion data (top trace), complete synthetic seismograms (second trace), and contributions from the northwest half (third trace-NW) and southeast half (bottom trace-SE) of the model fault. For each station, all traces are scaled to a common peak value. The surface projection of the strong-motion slip distribution is also shown.

our inversion models, we show slip vectors for individual subfaults in Figure 13. Maximum values for the absolute slips are given in Table 5. The average rake angles, based on the relative components strike slip and dip slip for the strong-motion, teleseismic, and combined inversions are $142^{\circ}, 144^{\circ}$, and $145^{\circ}$, 

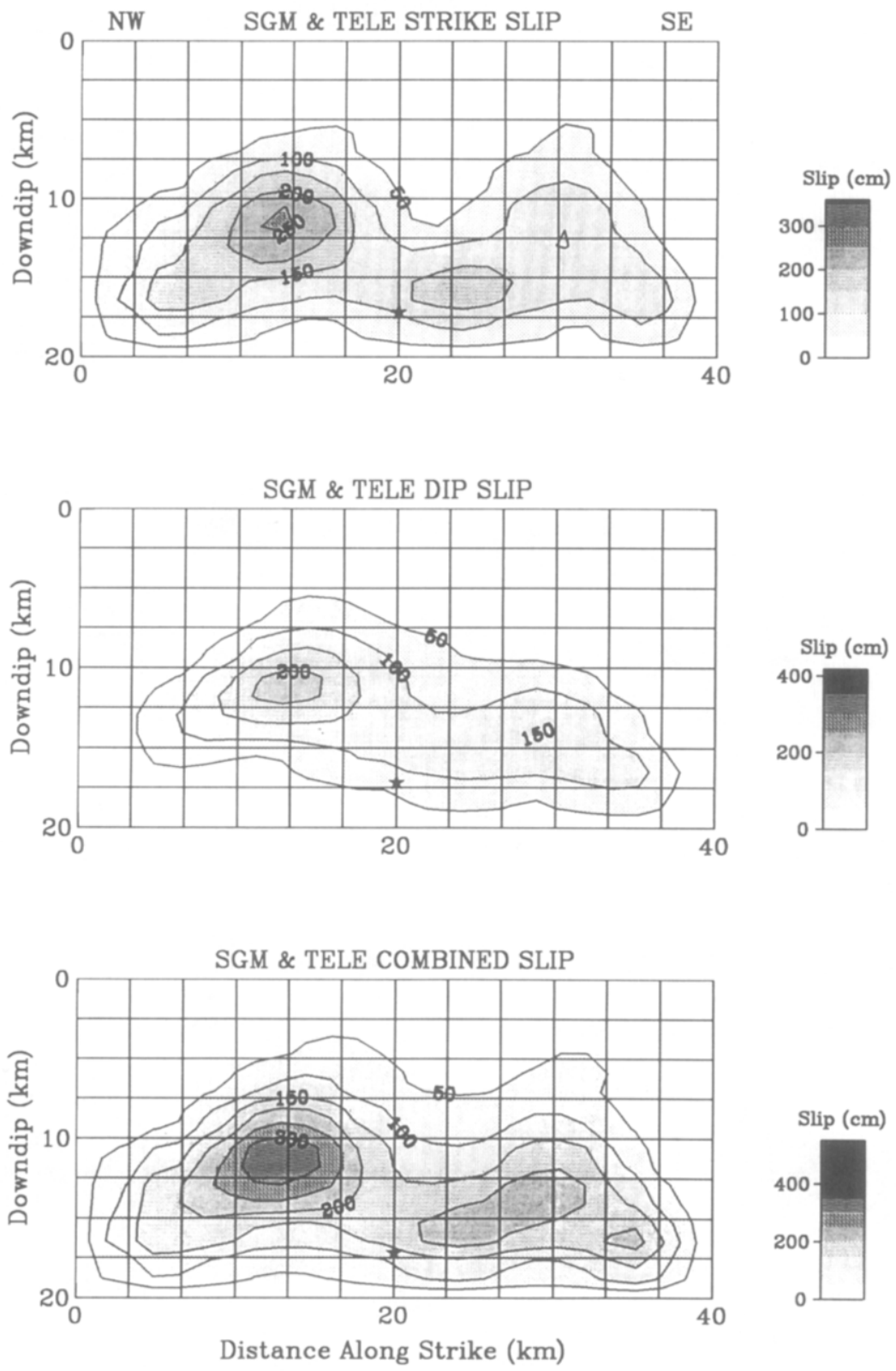

FIG. 12. Northwest-southeast cross section of the fault model showing contours of dislocation for strike-slip (top), dip-slip (middle), and oblique-slip (bottom) resulting from the combined strong-motion and teleseismic inversion. Contour interval is $50 \mathrm{~cm}$. Shading values indicating slip in $\mathrm{cm}$ are given by the scale to the right of each diagram.

respectively. This agrees well with the range of values given in the teleseismic point source studies of other researchers (Table 4) and with geodetic modeling results (Lisowski et al., 1990).

Inversion of only the teleseismic data does not result in systematic spatial variations of the rake angle (Fig. 13, middle). However, inversions using the strong-motion data (Figures 13, top and bottom) show a clear tendency for more 

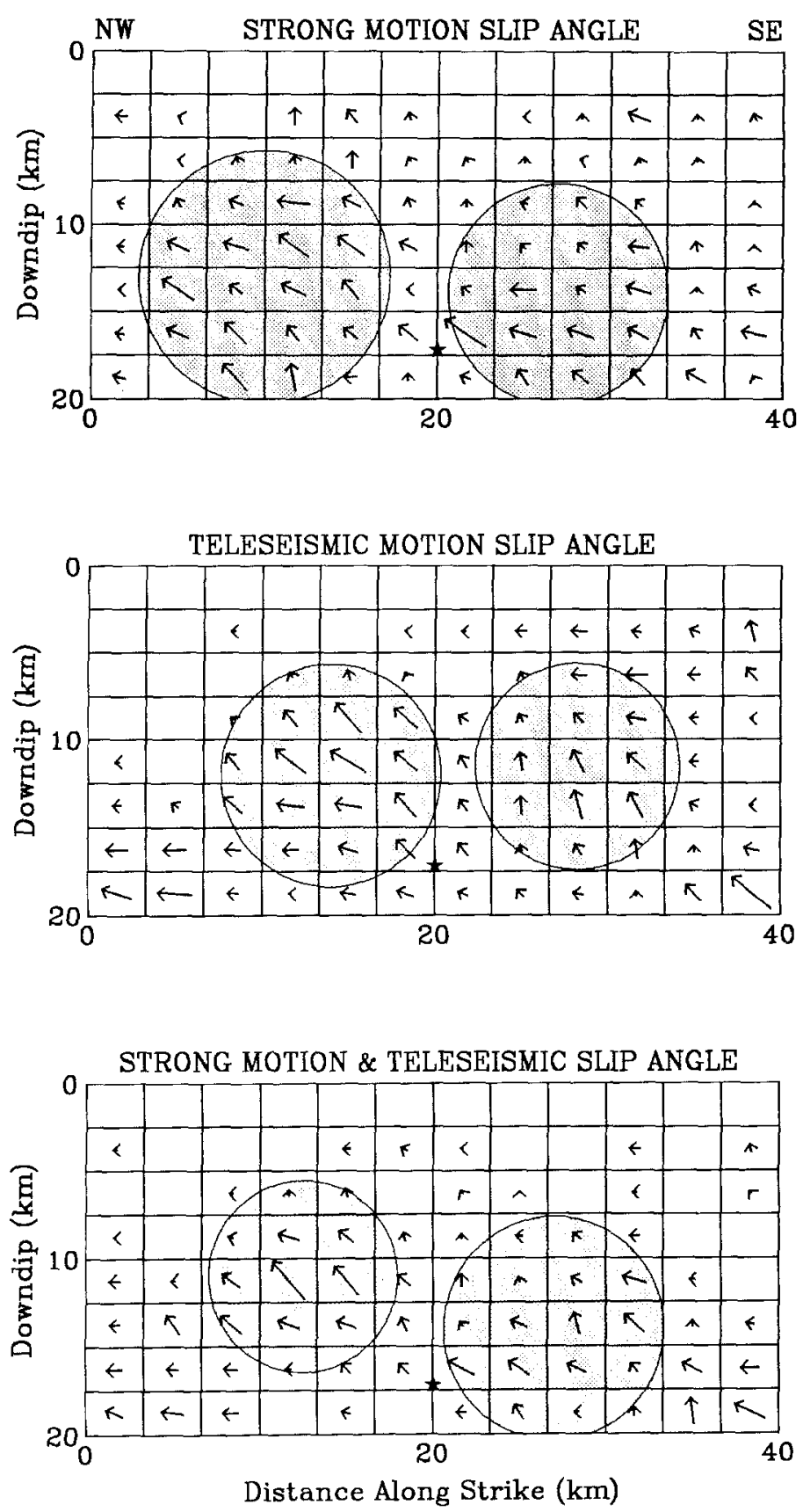

FIG. 13. Northwest-southeast cross section of the fault model showing the rake angle for each subfault as determined in each inversion. The length of the vector is proportional to the amount of slip, each normalized by the peak slip on the fault plane.

vertical rake angles for slip that is northwest of the hypocenter and for more horizontal rake angles for slip that is to the southeast. Although our models assume all slip occurs on a single $70^{\circ}$ dipping plane, this systematic change in rake angle coincides with an apparent change in the dip of the aftershock zone 
from about $70^{\circ}$ for the segment northwest of the hypocenter to nearly vertical near the southeastern edge of the fault plane (Dietz and Ellsworth, 1990).

One shortcoming of our model is its failure to produce the large amplitude transverse motions observed at HOL (Fig. 10b), although site response studies do indicate significant site amplifications at this station ( $K$. Aki, personal comm.). HOL is located along the southeast projection of the fault, and it has an unusually large motion perpendicular to the fault strike (Fig. 2b). Strike-slip faulting on a separate vertically dipping, southeast-trending fault plane located at the southeast end of the aftershock area (perhaps the San Andreas fault) is suggested by this waveform. The radiation pattern from a vertical strike-slip mechanism would greatly enhance the tangential component and yet not contribute to the near-nodal radial and vertical components. Such a model is consistent with the near vertical aftershock distribution and strike-slip mechanisms near the southeastern edge of the inferred rupture zone (Dietz and Ellsworth, 1990). Pure strike-slip motion occurs on the shallow, southeastern section of our fault inferred from the teleseismic data, but it is not seen in models inferred from strong-motion data.

To estimate the stress drop for the regions of concentrated slip, we approximate their area with a circular region and calculate the average slip within that region. The choice of regions for stress drop calculations are the shaded regions in Figure 13. The stress drop expression of Eshelby (1957) for a circular fault, $\Delta \sigma=(7 \pi / \mu \bar{u}) /(16 a)$ (where $\mu$ is the rigidity, $\bar{u}$ is the average dislocation, and $a$ is the radius) is used for this calculation. Using $\mu=3.4 \times 10^{11} \mathrm{dyne} / \mathrm{cm}^{2}$, we obtain the stress drop values given in Table 5. For the entire fault rupture, it is more appropriate to use the relationship of Parsons et al. (1988) for a long, buried, strike slip fault, $\Delta \sigma=(C \mu \bar{u}) /(w)$, where $w$ is the downdip fault width and $C$ is a constant dependent on the fault plane dimensions. Using our fault dimensions, their results require $C$ to be approximately equal to 1.75 . We use $w=17 \mathrm{~km}$ and have tabulated the stress drops for all three inversions in Table 5 .

In general, the rupture dimensions of significant slip agree well with the overall slip dimensions based on the active perimeter of the aftershock zone (Dietz and Ellsworth, 1990). This result is consistent with the observation of Mendoza and Hartzell (1988) that aftershocks often cluster along the margin of regions of the fault that experienced large co-seismic slips. The regions of major slip in our models coincide with a region of relatively few aftershocks in the central portion of the aftershock zone. However, our model suggests less updip rupture than inferred by Dietz and Ellsworth (1990) from the aftershock distribution alone. Hence, while the general features of the rupture may often be inferred from the aftershock activity, significant features of the rupture may be obscured in the aftershock patterns. The exact details of the aftershock pattern for this earthquake vary significantly depending on the time duration chosen for the analysis (see for example Dietz and Ellsworth, 1990, Figs. 3a through c). Consequently, we consider only the larger $(M>4.0)$ aftershocks including those within the first $34 \mathrm{~min}$ of the mainshock (Simila et al., 1990) and find a tendency for aftershocks to cluster around the major slip concentrations in our models (Fig. 9, bottom), particularly in the northwest region of the fault.

The use of three time windows (each having a duration of $0.7 \mathrm{sec}$ ) allows us to make general observations about the nature of the rupture velocity and slip time history. We expect regions requiring a locally slower rupture velocity to 
make use of the later time windows in order to compensate for the slower, fixed rupture velocity. Likewise, regions with a faster rupture velocity would take advantage of only the first rupture window. Overall, in both the strong-motion and teleseismic inversion, slip in the first window dominates, with minor slip occurring in the second and third windows (Fig. 14) over much of the fault. This implies that the rupture timing in our model satisfies the data and that large variations in the rupture velocity are unnecessary. There is some suggestion of
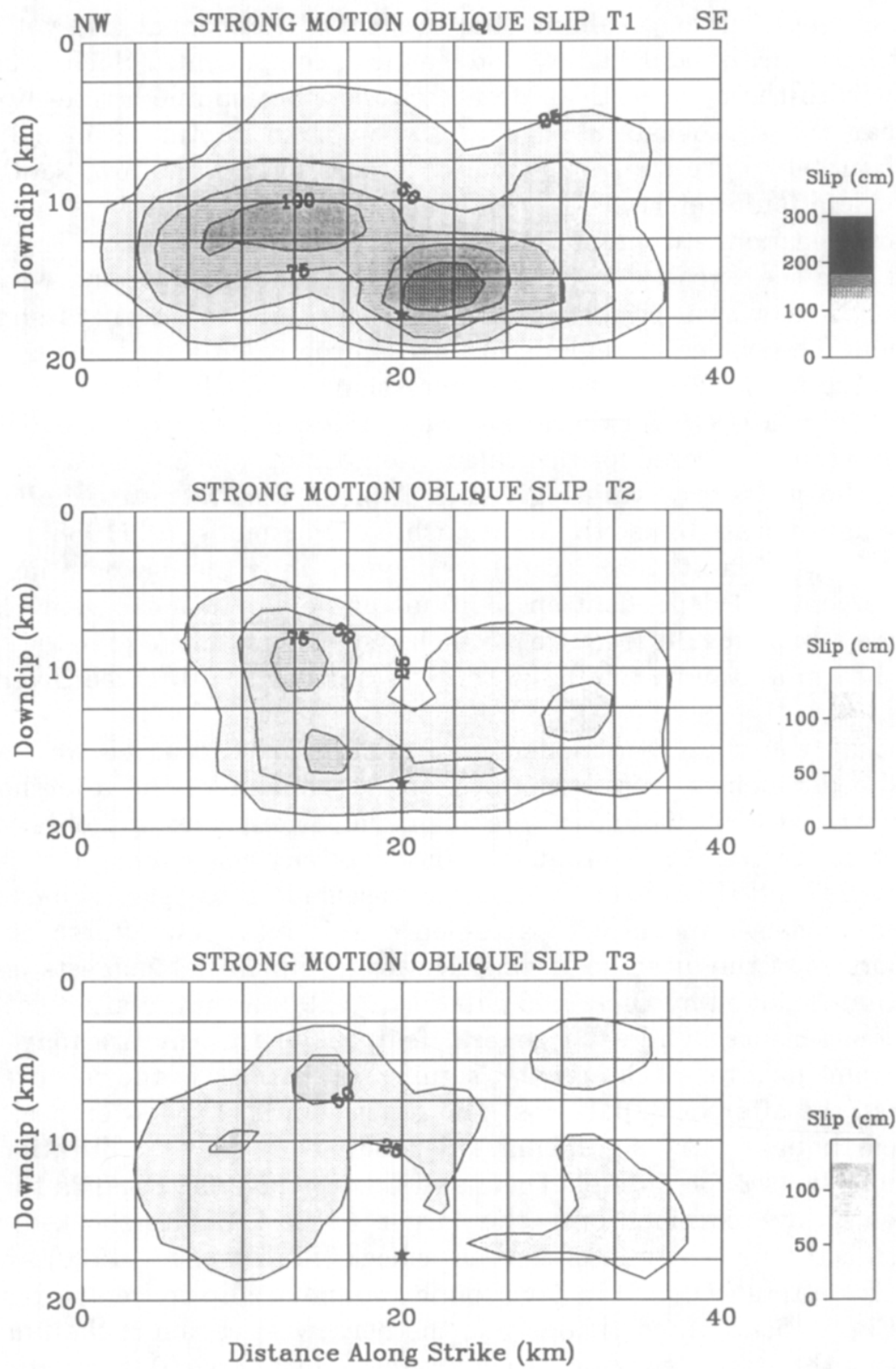

FIG. 14. Separate oblique-slip contributions for time window 1 (top), 2 (middle), and 3 (bottom) resulting from the strong-motion inversion. Each time window is separated by 0.6 sec. Contour interval is $25 \mathrm{~cm}$. 
locally slower rupture velocity or somewhat longer slip duration along the outer northwest margin of the northwestern asperity, the same region that exhibits the majority of $M>4.0$ aftershocks.

The fact that most of the slip is concentrated in the first time window indicates that our models prefer short slip durations (less than $1 \mathrm{sec}$ ) for a given point on the fault. This implies that only a small portion of the entire rupture surface is slipping at any given time. For example, the portion of the fault rupturing 5 sec after the nucleation time is depicted in Figure 3 as the shaded area within time window 1 . Short slip durations have been inferred for other earthquakes, and they have an important implication for rupture mechanics (Heaton, 1990).

\section{Conclusions}

From analysis of the three inversion results, we find a bilateral dislocation pattern with two main regions of oblique slip. One region is centered about 6 to $8 \mathrm{~km}$ northwest of the hypocenter at a depth of 11 to $13 \mathrm{~km}$, and the other is centered at 7 to $9 \mathrm{~km}$ southeast of the hypocenter near a depth of 15 to $16 \mathrm{~km}$. The northwestern patch has a larger moment, a higher average slip, and consequently a larger overall stress drop (Table 5). It is also the source of the largest observed strong-motion velocities recorded about $20 \mathrm{~km}$ northwest of the epicenter (See Figs. 2 and 11). Dominant radiation toward the northwest is also confirmed by the overall damage patterns and landslides concentrated in regions northwest of the epicenter (Benuska, 1990). Likewise, there is an azimuthal dependence to the peak ground motions as observed by Boore et al. (1989, Fig. 6). They note a tendency for high residuals relative to predicted peak values at rock sites toward the northwest compared to all other azimuths.

At the request of the Editor, we now compare our slip model with the other dislocation models presented in this volume (Beroza, 1991; Hartzell et al., 1991; Steidl et al., 1991). Although there are significant differences in the amplitude and direction of slip vectors between our model and others, there is also remarkable agreement in these models concerning the overall nature of this rupture. All researchers conclude that bilateral rupture with relatively little slip updip from the hypocenter best explains the waveforms. All researchers find that the majority of slip occurred in two relatively small patches nearly equidistant from the hypocenter: one to the northwest and one to the southeast. All studies indicate that a fairly uniform rupture velocity of approximately $80 \%$ of the local shear-wave velocity together with a relatively short slip duration at any point (less than about $1.5 \mathrm{sec}$ ) best explains the waveforms.

Although our model is similar in most respects to the others presented in this volume, it differs substantially in two aspects. First, the local rake vectors vary significantly among the models discussed here. On average, the rake vectors in the region southeast of the hypocenter for our model and that of Hartzell et al. (1991) agree and are about $145^{\circ}$. Both these models have similar oblique rake components in the northwestern asperity. In contrast, the southeastern asperity in the models of Beroza (1991) and Steidl et al. (1991) shows rake angles indicating nearly pure strike-slip (rake approximately 160 to $170^{\circ}$ ), yet have almost pure thrusting rake vectors $\left(80\right.$ to $\left.90^{\circ}\right)$ within the northwestern asperity. These two models require an approximately $80^{\circ}$ change in rake vector from the southern to northern halves of the fault with no corresponding change in dip. It should also be emphasized that, although the slip distributions of 
Hartzell et al. (1991) and Beroza (1991) look similar, the rake vector in the region of dominant slip for these models (the southeast asperity) is different by about $40^{\circ}$ and would likely produce substantially different near-field ground motions.

Second, in addition to the variation in the local rake directions, the partitioning of the total slip along strike in asperities northwest and southeast of the epicenter in our model requires more slip in the northwest region (Figs. 5, 9 and 13; Table 5); the other models require a majority of the slip in the southeast asperity. Considering that rise times, rupture velocities, and source geometries are similar among the various models, disparities in the resulting slip distribution models most likely reflect variations in the data sets employed. Other parameters being comparable, station coverage and weighting are perhaps the most critical elements controlling the slip partitioning. A source of dominant radiation northwest of the epicenter is required by the strong-motion data used in our study (see Fig. 2). In particular, the large, coherent arrivals at stations SAR, LEX and LGP require significant slip and directivity in that direction. A comparison of waveform fits at station SAR by the various models is particularly revealing and reflects the differences in modeling strategy.

The strategy adopted by Steidl et al. (1991) was to obtain the largest possible azimuthal coverage by including stations out to $60 \mathrm{~km}$. Thus, they modeled a number of distant stations to the north (FRE, FMS, WFS, CSS, and CSP) quite well, while doing a relatively poor job at SAR in fitting both waveform and amplitude. They did not use LEX and LGP, the two stations with the largest observed ground velocities, and therefore the wave field at these ray parameters is down-weighted relative to distant samples. If their Green's functions are adequate for these distant stations and ours prove less than desirable at LEX, SAR, and LGP, then they have a more reasonable interpretation. A detailed study of aftershock recordings at the various stations is one way to resolve this particular issue, since local receiver structures can be recognized and the adequacy of the theoretical Green's functions may be examined.

It is not so clear why the slip distribution model of Beroza (1991) has different characteristics than ours. Although he does not use the vertical components of the ground motion, his station selection in the northwest region of the fault is similar to that in our study. Waveforms fits at his northwestern stations show significant differences from those of our model. Perhaps the slip distribution variability is partially due to the differences in the applied Green's functions, as he suggests; we employed the complete layered space solutions, whereas he used only geometric ray approximations. Again, a comparison of near-field and far-field Green's functions with simple aftershocks at SAR and other stations should help resolve this issue.

Slip in the southeastern asperity is obviously constrained by the southeastern stations, as described in Figure 11. We used station WAT and a few of the Gilroy stations. We observed that the other Gilroy stations have complex receiver functions and omitted them. The data sets from the other studies excluded WAT and used additional stations from the Gilroy array. The use of a dense set of stations over a limited distance and azimuthal ranges provides redundant coverage and may favor slip in the southern portion of the fault plane.

Clearly, the teleseismic data has less resolving power along strike than the strong motion, as can be observed by comparison of $P$ and $S H$ waveforms from 
this study and those of Hartzell et al. (1991). Although the slip models are quite different, indeed they are nearly northwest-southeast reversed, they produce very similar teleseismic waveforms, which suggests a lack of resolution from this data set. The teleseismic data, however, does resolve updip directivity and requires a bilateral rupture with little updip slip. Again, it is most likely that the differences in the teleseismic models result from variations in station coverage. Hartzell et al. (1991) use similar teleseismic stations to ours, but they add several additional stations, particularly in the northwestern and northeastern azimuths. These additions do not substantially augment azimuthal coverage and may actually bias the result. Removal of these stations from their inversion results in a model similar to our results, favoring northwestern slip (Steve Hartzell, personal comm.).

It is important to note that, even though the slip distribution and rake vectors vary, the net sum of any of these models will be very similar at long periods. This can be explained by the fact that the bilateral rupture radiates from both asperities simultaneously. Hence, as long as the net rake vector and total moment are preserved, the resulting models should produce similar and adequate teleseismic waveform matches. This, however, is not true for the near-field data. That the waveform comparisons for all the strong-motion models are less than remarkable may reflect the need for a more complex rupture surface than the idealized flat planar models used here.

In general, the rupture process of the Loma Prieta earthquake was fairly simple for a magnitude 7.1 earthquake, rupturing only a relatively short $(<35$ $\mathrm{km}$ ) fault segment (Kanamori and Satake, 1990). The relatively short duration of strong motion can be partially attributed to the bilateral nature of the rupture. Further, the relatively large depth of slip concentrations had the effect of moderating the size of the ground velocities in the near-source region.

Most of our current knowledge of fault asperity characteristics has been derived from ground-motion frequencies that are lower $(<1 \mathrm{~Hz})$ than the frequency range of most interest in earthquake engineering. Wald et al. (1987, 1988) found that large-scale asperity models derived from longer-period velocity data also explained many characteristics of the higher-frequency accelerograms. Our results here indicate that the asperities that control the broadband teleseismic waveforms ( 3 to $30 \mathrm{sec}$ ) also dominate the higher-frequency strong motions ( 1 to $5 \mathrm{sec}$ ).

In an effort to understand the radiation of the higher frequency motions during the Loma Prieta earthquake, we have performed an inversion with the observations and synthetic seismograms bandpassed filtered from 0.1 to $3 \mathrm{~Hz}$. We used a finer discretization of the fault plane, with 200 subfaults each having dimensions of $2.0 \mathrm{~km}$ along strike and $2.0 \mathrm{~km}$ downdip. We also reduced the duration of the source-time-function to $0.5 \mathrm{sec}$. Our results indicate that the same regions of large slip that control the longer period teleseismic waveforms and the strong-motion velocities up to $1 \mathrm{~Hz}$ are also responsible for higher-frequency $(>1.0 \mathrm{~Hz}$ ) radiation. We also note that the inversion using higher-frequency data appears to favor slightly more concentrated asperities. Understanding the relationship between long-period source models of large earthquakes and the radiation of high frequencies is critical for the prediction of ground motions in the frequency range of engineering interest. Future work will address the nature of the high-frequency radiation further. This will require more sophisticated timing corrections based on the aftershock data 
recorded at many of the strong-motion stations used here and a more detailed treatment of the variations in propagation paths and site effects of individual stations.

\section{ACKNOWLEDGMENTS}

Reviews of Hiroo Kanamori, Paul Somerville, and Lisa Wald improved the original manuscript. We thank Steve Hartzell for useful discussions and advice on the use of his inversion software. This work was supported by the U.S. Geological Survey under contracts 14-08-0001-21912 and 14-080001-G1832. Contribution No. 4935, Division of Geological and Planetary Sciences, California Institute of Technology, Pasadena, California.

\section{REFERENCES}

Archuleta, R. (1984). A finite faulting model for the 1979 Imperial Valley, California, earthquake, J. Geophys. Res. 89, 4559-4585.

Barker, J. S. and D. H. Salzberg (1990). Long-period and broad-band teleseismic body-wave modeling of the Loma Prieta earthquake, Geophys. Res. Lett. 17, 1409-1412.

Benuska, L. (1990). Loma Prieta Earthquake Reconaissance Report, Earthquake Spectra 6, Suppl., 448.

Beroza, G. C. (1991). Near-source modeling of the Loma Prieta earthquake: evidence for heterogeneous slip and implications for earthquake hazard, Bull. Seism. Soc. Am. 81, 1603-1621.

Beroza, G. C. and P. Spudich (1988). Linearized inversion for fault rupture behavior: application to the 1984 Morgan Hill, California, earthquake, Bull. Seism. Soc. Am. 78, 6275-6296.

Boore, D. M., L. Seekins, and W. B. Joyner (1989). Peak accelerations from the 17 October 1989 Loma Prieta earthquake, Seism. Res. Lett. 60, 151-156.

Choy G. L. and J. Boatwright (1990). Source characteristics of the Loma Prieta, California, earthquake of October 18, 1989 from global digital seismic data, Geophys. Res. Lett. 17, 1183-1189.

Dietz, L. D. and W. L. Ellsworth (1990). The October 17, 1989, Loma Prieta, California, earthquake and its aftershocks: geometry of the sequence from high-resolution locations, Geophys. Res. Lett. 17, 1417-1420.

Eberhart-Phillips D., V. F. Labson, W. D. Stanley, A. J. Michael, and B. D. Rodriquez (1990). Preliminary velacity and resistivity model of the Loma Prieta earthquake region, Geophys. Res. Lett. 17, 1235-1238.

Eshelby, J. D. (1957). The determination of the elastic field of an ellipsoidal inclusion and related problems, Proc. Roy. Soc. London, Series A 241, 376-396.

Futterman, W. I. (1962). Dispersive body waves, J. Geophys. Res. 67, 5279-5291.

Hartzell, S. H. (1989). Comparison of seismic waveform inversion techniques for the rupture history of a finite fault: application to the 1989 North Palm Springs, California, earthquake, J. Geophys. Res. 94, 7515-7534.

Hartzell, S. H., G. S. Stewart, and C. Mendoza (1991). Comparison of $L_{1}$ and $L_{2}$ norms in a teleseismic inversion for the slip history of the Loma Prieta, California, earthquake, Bull. Seism. Soc Am. 81, 1518-1539.

Hartzell, S. H. and T. H. Heaton (1983). Inversion of strong ground motion and teleseismic waveform data for the fault rupture history of the 1979 Imperial Valley, California earthquake, Bull. Seism. Soc Am. 73, 1553-1583.

Hartzell, S. H. and T. H. Heaton (1986). Rupture history of the 1984 Morgan Hill, California, earthquake from the inversion of strong motion records, Bull. Seism. Soc Am. 76, 649-674.

Hartzell, S. H. and C. Mendoza (1991). Application of an iterative least squares waveform inversion of strong motion and teleseismic records to the 1978 Tabas, Iran, earthquake, Bull. Seism. Soc. Am. 81, 305-331.

Heaton, T. H. (1982). The 1971 San Fernando earthquake: a double event?, Bull. Seism. Soc. Am. $72,2037-2062$.

Heaton, T. H. and R. E. Heaton (1989). Static deformations from point forces and force couples located in welded elastic poissonian half-spaces: implications for seismic moment tensors, Bull. Seism. Soc. Am. 79, 813-841.

Heaton, T. H. (1990). Evidence for and implications for self-healing pulses of slip in earthquake rupture, Phys. Earth Planet. Interiors 64, 1-20. 
Jennings, C. W. (1975). Fault map of California, with locations of volcanoes, thermal springs, and thermal wells, California Division of Mines and Geology, Geologic Data Map 1, scale 1:750,000.

Kanamori, H. and K. Satake (1990). Broadband study of the 1989 Loma Prieta earthquake, Geophys. Res. Lett. 17, 1179-1182.

King, G. C. P., A. G. Lindh, and D. H. Oppenheimer (1990). Seismic slip, segmentation, and the Loma Prieta earthquake, Geophys. Res. Lett. 17, 1449-1452.

Langston, C. A. and D. V. Helmberger (1975). A procedure for modeling shallow dislocation sources, Geophys. J. 42, 117-130.

Langston, C. A., K. P. Furlong, K. S. Vogfjord, R. H. Clouser, and C. J. Ammon (1990). Analysis of teleseismic body waves radiated from the Loma Prieta earthquake, Geophys. Res. Lett. 17, 1405-1408.

Lisowski, M., W. H. Prescott, J. C. Savage, and M. J. Johnston (1990). Geodetic estimate of coseismic slip during the 1989 Loma Prieta, California, earthquake, Geophys. Res. Lett. 17, 1437-1440.

Maley, R., A. Acosta, F. Ellis, E. Etheredge, L. Foote, D. Johnston, R. Pocella, M. Salsman, and J. Switzer (1989). U.S. Geological Survey strong-motion records from the northern California (Loma Prieta) earthquake of October 17, 1989, U.S. Geol. Surv. Open-File Rept. 89-568.

Mendoza, C. and S. H. Hartzell (1988). Aftershock patterns and mainshock faulting, Bull. Seism. Soc. Am. 78, 1438-1449.

Nábělek, J. (1990). Rupture process of the October 18, 1989 Loma Prieta earthquake from broadband teleseismic body waves, Presented at SSA meeting, Santa Cruz, 2-4 May, 1990.

Olson, A. H. and R. J. Apsel (1982). Finite faults and inverse theory with applications to the 1979 Imperial Valley earthquake, Bull. Seism. Soc. Am. 72, 1969-2001.

Olson, A. H., J. Orcutt, and G. Frazier (1984). The discrete wavenumber/finite element method for synthetic seismograms, Geophys. J. R. Astr. Soc. 77, 421-460.

Olson, J. A. (1990). Seismicity in the twenty years preceding the Loma Prieta, California, earthquake, Geophys. Res. Lett. 17, 1429-1432.

Oppenheimer, D. H. (1990) Aftershock slip behavior of the 1989 Loma Prieta, California, earthquake, Geophys. Res. Lett. 17, 1199-1202.

Parsons, I. D., J. F. Hall, and G. A. Lyzenga (1988). Relationships between the average offset and the stress drop for two- and three-dimensional faults, Bull. Seism. Soc. Am. 78, 931-945.

Romanowicz, B. and H. Lyon-Caen (1990). The Loma Prieta earthquake of October 18, 1989: results of teleseismic mantle and body wave inversion, Geophys. Res. Lett. 17, 1191-1194.

Ruff, L. J. and B. W. Tichlarr (1990). Moment tensor rate functions for the 1989 Loma Prieta earthquake, Geophys. Res. Lett. 17, 1187-1190.

Schwartz, S. Y., D. L. Orange, and R. S. Anderson (1990). Complex fault interactions in a restraining bend on the San Andreas Fault, Southern Santa Cruz Mountains, California, Geophys. Res. Lett. 17, 1207-1210.

Seeber, L. and J. G. Armbruster (1990). Fault kinematics in the 1989 Loma Prieta rupture area during 20 years before the event, Geophys. Res. Lett. 17, 1425-1428.

Shakal, A., M. Huang, M. Reichle, C. Ventura, T. Cao, R. Sherburne, M. Savage, R. Darragh, and C. Petersen (1989). CSMIP strong motion records from the Santa Cruz Mountains (Loma Prieta), California, earthquake of 17 October 1989, Report No. OSMS 89-06, California Strong Motion Instrumentation Program, $196 \mathrm{pp}$.

Simila, G. W., K. C. McNally, E. Nava, M. Protti-Quesada, and J. Yellin (1990). Evidence of very early aftershock activity along the northwest portion of the 18 October 1989 earthquake rupture zone, Geophys. Res. Lett. 17, 1785-1788.

Steidl, J. H., R. J. Archuleta, and S. Harzell (1991). Rupture history of the 1989 Loma Prieta, California, earthquake, Bull. Seism. Soc Am. 81, 1573-1602.

Stover, C. W., B. G. Reagor, F. W. Baldwin, and L. R. Brewer (1990). Preliminary isoseismals map for the Santa Cruz (Loma Prieta), California, earthquake of October 18, 1989 UTC, U.S. Geol. Surv. Open-File Rept. 90-18, 24 pp.

U.S. Geological Survey Staff (1990). The Loma Prieta, California, earthquake: an anticipated event, Science 247, 286-293.

Wald, D. J., P. G. Somerville, and D. V. Helmberger (1987). Compatibility of accelerograms of the 1979 Imperial Valley, California, earthquake with slip-distribution asperity models, Seism. Res. Lett. 58, 59.

Wald, D. J., L. J. Burdick, and P. G. Somerville (1988). Simulation of acceleration time histories close to large earthquakes, in Proc. Earthquake Engineering and Soil Dynamics II Conf. American Society of Civil Engineers, Geotechnical Special Publication No. 20, 430-444. 
Wald, D. J., D. V. Helmberger, and S. H. Hartzell (1990). Rupture process of the 1987 Superstitions Hills earthquake from the inversion of strong motion data, Bull. Seism. Soc. Am. 80, $1079-1098$.

Wald, D. J, D. V. Helmberger, and T. H. Heaton (1991). The rupture initiation process of a large earthquake: Loma Prieta, Seism. Res. Lett. 62, 29.

Wallace, T. C. (1990). Source model for the Loma Prieta earthquake from regional and teleseismic bodywaves, Presented at the SSA Meeting, Santa Cruz, 2-4 May, 1990.

Working Group on California Earthquake Probabilities (1988). Probabilities of large earthquakes occurring in California on the San Andreas Fault, U.S. Geol. Surv. Open-File Rept. 88-398, 62 pp.

Zhang, J. and T. Lay (1990). Source parameters of the 1989 Loma Prieta earthquake determined from long-period Rayleigh waves, Geophys. Res. Lett. 17, 1195-1198.

SEismological LaboRATORY

California Institute of Technology

Pasadena, California 91125

(D.J.W., D.V.H)

Manuscript received 18 October 1990
U.S. Geological Survey 525 S. WiLson Avenue

Pasadena, California, 91106 (T.H.H.) 